Methods of Analysis by the U.S. Geological Survey National Water Quality Laboratory-Determination of Organophosphate Pesticides in Bottom Sediment by Gas Chromatography with Flame Photometric Detection

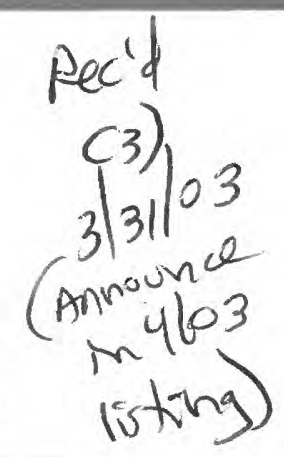

Water-Resources Investigations Report 02-4222 
Methods of Analysis by the U.S. Geological Survey National Water Quality Laboratory-Determination of Organophosphate Pesticides in Bottom Sediment by Gas Chromatography with Flame Photometric Detection

By Virendra K. Jha and Duane S. Wydoski

U.S. Geological Survey

Water-Resources Investigations Report 02-4222 


\section{U.S. DEPARTMENT OF THE INTERIOR}

Gale A. Norton, Secretary

U.S. GEOLOGICAL SURVEY

Charles G. Groat, Director

The use of trade, product, or firm names in this report is for descriptive purposes only and does not imply endorsement by the U.S. Government.

For additional information write to:

U.S. Geological Survey

Chief, National Water Quality Laboratory

Box 25046, Mail Stop 407

Federal Center

Denver, Co 80225-0046
Copies of this report can be purchased from:

U.S. Geological Survey

Branch of Information Services

Box 25286

Federal Center

Denver, CO 80225-0286 


\section{CONTENTS}

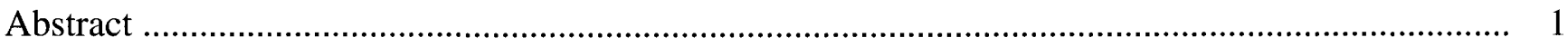

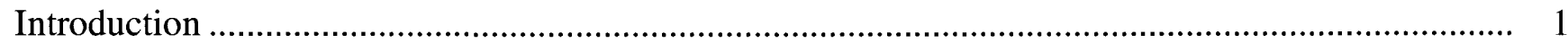

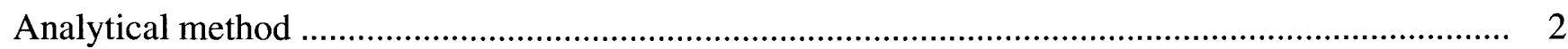

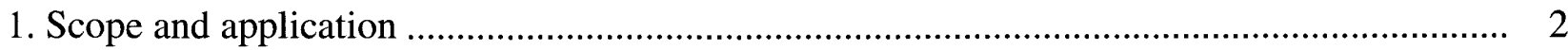

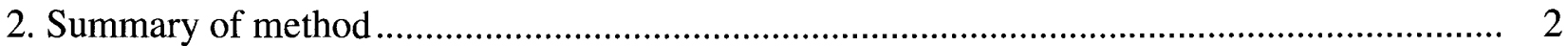

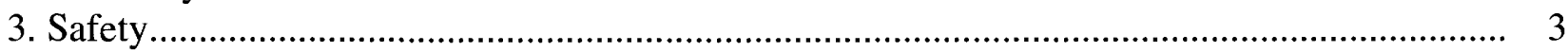

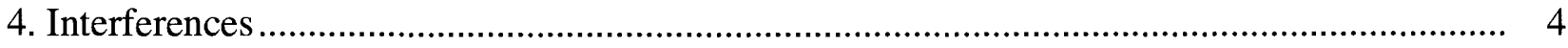

5. Collection, shipment, and storage of sediment samples ....................................................... 4

6. Apparatus and instrumentation...................................................................................... 4

7. Reagents and consumable materials................................................................................ 6

8. Calibration and quality-control standards and criteria .......................................................... 7

9. Sample preparation procedure.......................................................................................... 9

10. Gas chromatography/flame photometric detection analysis.................................................. 12

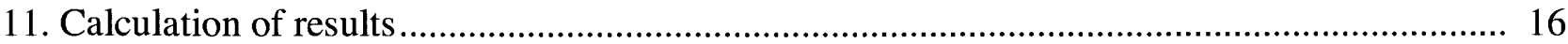

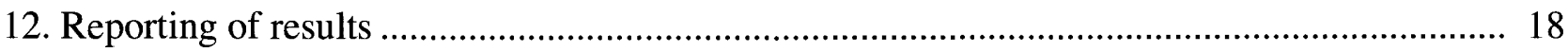

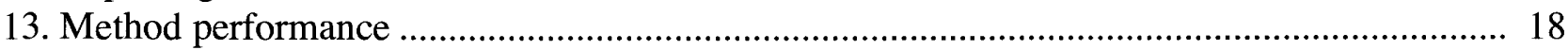

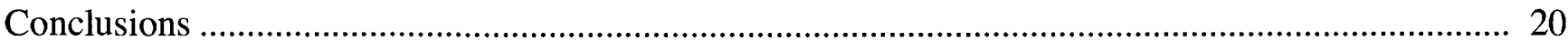

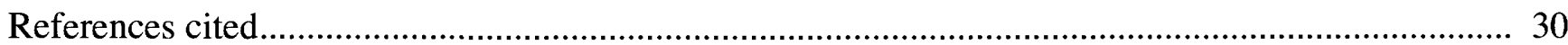

\section{FIGURES}

1. Gel permeation chromatogram of the fraction test solution at attenuation 8 showing analyst-determined start and end times for the organophosphate pesticde fraction.

2. Gas chromatogram with flame photometric detection of a 50-picograms-per-microliter calibration standard solution of the individual organophosphate pestices on a Restek Rtx-5 column

3. Gas chromatogram with flame photometric detection of a 50-picograms-per-microliter calibration standard solution of the individual organophosphate pesticides on a

Restek Rtx-1701 column

\section{TABLES}

1. Parameter codes, laboratory codes, and Chemical Abstracts Service registry numbers for method compounds

2. Suggested gel permeation chromatography processing sequence ……….............................. 12

3. Retention times of method compounds on the Rtx-5 and Rtx-1701 columns .......................... 13

4. Suggested gas chromatography/flame photometric detection autosequence .............................. 16

5. Initial laboratory reporting levels ................................................................................. 18 
6. Bias and variability of method compounds spiked at 8 micrograms per kilogram in reagent sodium sulfate and estimated method detection limit

7. Bias and variability from eight determinations of the method compounds spiked at 8 micrograms per kilogram in reagent sodium sulfate

8. Bias and variability from seven determinations of the method compounds spiked at 40 micrograms per kilogram in reagent sodium sulfate

9. Bias and variability from five determinations of the method compounds spiked at 80 micrograms per kilogram in reagent sodium sulfate

10. Bias and variability from seven determinations of the method compounds spiked at 8 micrograms per kilogram in Evergreen Lake sediment (Evergreen, Colo.)

11. Bias and variability from eight determinations of the method compounds spiked at 40 micrograms per kilogram in Evergreen Lake sediment (Evergreen, Colo.)

12. Bias and variability from eight determinations of the method compounds spiked at 80 micrograms per kilogram in Evergreen Lake sediment (Evergreen, Colo.)

13. Bias and variability from seven determinations of the method compounds spiked at 8 micrograms per kilogram in Clear Creek sediment (near Central City, Colo.

14. Bias and variability from eight determinations of the method compounds spiked at 40 micrograms per kilogram in Clear Creek sediment (near Central City, Colo.).

15. Bias and variability from eight determinations of the method compounds spiked at 80 mirograms per kilogram in Clear Creek sediment (near Central City, Colo.)

16. Compounds tested and deleted from this method because of very poor flame photometric detection response. 


\begin{tabular}{rll}
\hline Multiply & \multicolumn{1}{c}{ By } & To obtain \\
\hline centimeter $(\mathrm{cm})$ & $3.94 \times 10^{-1}$ & inch \\
gram $(\mathrm{g})$ & $3.53 \times 10^{-2}$ & ounce, avoirdupois \\
kilopascal $(\mathrm{kPa})$ & $1.45 \times 10^{-1}$ & pounds per square inch \\
liter $(\mathrm{L})$ & $2.64 \times 10^{-1}$ & gallon \\
meter $(\mathrm{m})$ & $3.94 \times 10^{1}$ & inch \\
microgram $(\mu \mathrm{g})$ & $3.53 \times 10^{-8}$ & ounce, avoirdupois \\
microliter $(\mu \mathrm{L})$ & $2.64 \times 10^{-7}$ & gallon \\
micrometer $(\mu \mathrm{m})$ & $3.94 \times 10^{-5}$ & inch \\
milligram $(\mathrm{mg})$ & $3.53 \times 10^{-5}$ & ounce, avoirdupois \\
milliliter $(\mathrm{mL})$ & $2.64 \times 10^{-4}$ & gallon \\
millimeter $(\mathrm{mm})$ & $3.94 \times 10^{-2}$ & inch \\
nanogram $(\mathrm{ng})$ & $3.53 \times 10^{-11}$ & ounce, avoirdupois \\
nanometer $(\mathrm{nm})$ & $3.94 \times 10^{-8}$ & inch \\
\hline
\end{tabular}

Degree Celsius $\left({ }^{\circ} \mathrm{C}\right)$ may be converted to degree Fahrenheit $\left({ }^{\circ} \mathrm{F}\right)$ by using the following equation:

$$
{ }^{\circ} \mathrm{F}=9 / 5\left({ }^{\circ} \mathrm{C}\right)+32 .
$$

The following abbreviations are also used in this report:

\begin{tabular}{|c|c|c|c|}
\hline BNA & base neutral acid & $\mu \mathrm{g} / \mathrm{kg}$ & microgram per kilogram \\
\hline $\mathrm{CCV}$ & continuing calibration verification standard & $\mu \mathrm{g} / \mathrm{mL}$ & microgram per milliliter \\
\hline $\mathrm{cm} / \mathrm{sec}$ & centimeters per second & USEPA & U.S. Environmental Protection Agency \\
\hline FPD & flame photometric detector & USGS & U.S. Geological Survey \\
\hline GC & gas chromatograph & SOP & standard operating procedure \\
\hline GC/FPD & gas chromatograph/flame photometric detector & TPC & third-party check standard \\
\hline GPC & gel permeation chromatography & & \\
\hline HPLC & high-performance liquid chromatography & & \\
\hline ID & inside diameter & & \\
\hline K-D & Kuderna-Danish & & \\
\hline LRB & laboratory reagent blank & & \\
\hline LRS & laboratory reagent spike & & \\
\hline LT-MDL & long-term method detection level & & \\
\hline MDL & method detection limit & & \\
\hline $\mathrm{mL} / \mathrm{min}$ & milliliter per minute & & \\
\hline MRL & minimum reporting level & & \\
\hline MSDS & Material Safety Data Sheet & & \\
\hline NAWQA & National Water-Quality Assessment Program & & \\
\hline NWQL & National Water Quality Laboratory & & \\
\hline $\mathrm{OC}$ & organochlorine & & \\
\hline OP & organophosphate pesticides & & \\
\hline $\mathrm{pg} / \mathrm{L}$ & picogram per liter & & \\
\hline $\mathrm{pg} / \mu \mathrm{L}$ & picogram per microliter & & \\
\hline PTFE & polytetrafluoroethylene & & \\
\hline QC & quality control & & \\
\hline $\mathrm{rpm}$ & revolutions per minute & & \\
\hline RT & retention time & & \\
\hline
\end{tabular}




\section{GLOSSARY}

Compound. The pesticide or pesticide degradate determined in an analysis.

Continuing calibration verification (CCV). The $\mathrm{CCV}$ is a calibration standard containing method compounds. It is used to measure and control the bias of the present calibration curve for these compounds. The CCV is an instrumental standard only and is not processed through preparative steps of the method.

Fortified reagent set spike. A quality-control sample prepared by adding a known amount of compounds to a reagent-sodium sulfate sample and analyzed with each set of environmental samples (usually 10). Also known as a "set spike."

Laboratory reporting level (LRL). The concentration where the false-positive error is minimized to no more than 1 percent and the false-negative error is minimized to no more than 1 percent. The LRL is calculated as 2 times the method detection limit. A compound that is not identified, confirmed, or measured in a sample is reported as $<\mathrm{LRL}$.

Method detection limit (MDL). The minimum concentration of a compound that can be measured and reported with 99-percent confidence that the compound concentration is greater than zero. At this concentration, the false-positive error is minimized to no more than 1-percent probability (U.S. Environmental Protection Agency, 1997).

Minimum reporting level (MRL). Lowest measured concentration of a constituent that may be reliably reported by using a given analytical method.

Surrogate. A compound not expected to be found in any environmental sample that is added to every sample in a known amount prior to sample processing. The surrogate is used to monitor method performance for each sample. 


\title{
Methods of Analysis by the U.S. Geological Survey National Water Quality Laboratory-Determination of Organophosphate Pesticides in Bottom Sediment by Gas Chromatography with Flame Photometric Detection
}

\author{
By Virendra K. Jha and Duane S. Wydoski
}

\begin{abstract}
A method for the isolation of 20 parent organophosphate pesticides and 5 pesticide degradates from bottom-sediment samples is described. The compound O-ethyl-O-methyl-S-propylphosphorothioate is reported as an estimated concentration because of variable performance. In this method, the sediment samples are centrifuged to remove excess water mixed with anhydrous sodium sulfate and Soxhlet extracted overnight with dichloromethane (93 percent) and methanol ( 7 percent). The extract is concentrated and then filtered through a 0.2 micrometer polytetrafluoroethylene membrane syringe filter. An aliquot of the sample extract is quantitatively injected onto two polystyrene-divinylbenzene gelpermeation chromatographic columns connected in series. The compounds are eluted with dichloromethane and a fraction is collected for analysis, with some coextracted interferences, including elemental sulfur, separated and discarded. The aliquot is concentrated and solvent exchanged to ethyl acetate. The extract is analyzed by dual capillary-column gas chromatography with flame photometric detection. Single-operator method detection limits in sodium sulfate matrix samples ranged from 0.81 to 2 micrograms per kilogram. Method performance was validated by spiking all compounds into three different solid matrices (sodium sulfate, bed sediment from Clear Creek, and bed sediment from Evergreen Lake) at three different concentrations. Eight replicates were analyzed at each concentration in each matrix. Mean recoveries of method compounds spiked in Clear Creek samples ranged from 43 to 110 percent, and those in
\end{abstract}

Evergreen Lake samples ranged from 62 to 118 percent for all pesticides. Mean recoveries of method compounds spiked in reagent sodium sulfate samples ranged from 41 to 101 percent for all pesticides. The only exception was O-ethyl-O-methyl-S-

propylphosphorothioate, which had an average recovery of 35 percent, and, thus, sample concentration is reported as estimated (" $E$ " remark code).

\section{INTRODUCTION}

Hydrophobic organic compounds, including many organophosphate (OP) pesticides, may be associated with solids in hydrologic environments (Smith and others, 1988). Both particle size and the amount of heterogeneous organic matter influence concentrations of solids-associated compounds. The method described in this report was developed to extract hydrophobic compounds, including OPs, from a sediment or soil matrix and partially isolate the compounds from coextracted natural organic matter prior to instrumental analysis. This method is applicable to bed-sediment (lake and stream), aqueous suspended-sediment, and soil samples.

Before 2003, the U.S. Geological Survey (USGS) National Water Quality Laboratory (NWQL) determined recoverable organophosphate pesticides in bottom sediment by using the USGS method described by Wershaw and others (1987) (method O-5104-83; NWQL laboratory schedule 1320). This method consisted of extracting bottom-sediment samples with dichloromethane and analyzing the concentrated extracts by using packed-column gas chromatography 
with flame-photometric detectors. In 1990, the packed-column technology was replaced by capillarycolumn technology ( 0.25 -mm diameter). The original method (Wershaw and others, 1987) included only six compounds (diazinon, ethion, malathion, methyl parathion, parathion, and trithion).

With the present (2003) method, the NWQL has developed a new bottom-sediment method that uses a gel-permeation chromatography (GPC) procedure to improve organophosphate pesticide isolation from coextracted interferences. This new method also expands the selected list of determined compounds from 6 to 25, and one of the compounds, O-ethyl-Omethyl-S-propylphosphorothioate, ${ }^{1}$ is permanently reported with an estimated remark code because of lower-than-acceptable performance. One OP, Isofenfos, is used as a surrogate standard because it is not expected to be found in bottom-sediment samples collected in the United States.

There are substantial advantages of using this method over previously used methods. The extensive preparation protocol of the new method provides cleaner extracts, thereby increasing signal-to-noise ratios, improving reproducibility, and thus, method detection limits. The GPC step removes or greatly reduces the inorganic sulfur in the extract, which can interfere during analysis by the element-selective detector used in this method.

This method report addresses the following topics: principles and application of the method, apparatus and reagents required, details of the preparation and analytical procedures, calculations, reporting of results (units and significant figures), and method performance. The method supplements other methods of the USGS for the determination of organic substances that have been described by Wershaw and others (1987), Fishman (1993), and Jha and Wydoski (2002). The new method was implemented as a custom method at the NWQL in January 2003.

${ }^{1}$ A short, 20-character name was used in the tables to minimize space taken by lengthy chemical names. The short name was defined as the first 14 characters and the last 5 characters of name, joined by an underscore: "_. Common or chemical names and corresponding short names are listed in table 1.

\section{ANALYTICAL METHOD}

\section{Organic Compounds and Parameter Codes: Organophosphate pesticides, bottom sediment, high-performance gel- permeation chromatography, gas chromatography, $0-5404-02$ (see table 1)}

\section{Scope and Application}

This method is suitable for the determination of 20 parent organophosphate pesticides (OPs) and 5 related OP degradation products specified in table 1 in bedsediment (lake and stream), aqueous suspendedsediment, and soil samples. One of the compounds, O-ethyl-O-methioate, is permanently reported with an estimated concentration because of variable instrumental and extraction stability problems. This method is applicable to the determination of pesticides and pesticide degradates that are (1) efficiently extracted from the solid matrix by methanol and dichloromethane, (2) adequately separated from natural coextracted compounds by gel permeation chromatography, (3) chromatographically resolved and identified by using a gas chromatograph (GC) equipped with flame photometric detectors (FPD), and (4) sufficiently stable to chemical and thermal degradation to allow accurate quantification by using all sampling and analysis steps of the method. Method compounds and their parameter codes, laboratory codes, and Chemical Abstracts Service (CAS) numbers for each compound are listed in table 1.

\section{Summary of Method}

\subsection{Minimum sample size of about 25-g} equivalent dry-weight sample, accurately weighed, is extracted with Soxhlet apparatus using $350 \mathrm{~mL}$ dichloromethane and $25 \mathrm{~mL}$ methanol (93:7 ratio).

2.2 The extract is concentrated and then filtered through a syringe filter containing a $0.2-\mu \mathrm{m}$ polytetrafluoroethylene membrane.

\section{$2.3 \quad 1,400-\mathrm{L}$ aliquot of the sample extract is} injected quantitatively onto two linked styrenedivinylbenzene gel-permeation chromatographic columns and eluted with dichloromethane.

2.4 The aliquot is concentrated and solvent exchanged to ethyl acetate. 
Table 1. Parameter codes, laboratory codes, and Chemical Abstracts Service registry numbers for method compounds

[CAS, Chemical Abstracts Service]

\begin{tabular}{lccc}
\hline \multicolumn{1}{c}{ Organophosphate pesticide or degradate } & $\begin{array}{c}\text { Parameter } \\
\text { code }\end{array}$ & $\begin{array}{c}\text { Laboratory } \\
\text { code }\end{array}$ & $\begin{array}{c}\text { CAS } \\
\text { number }\end{array}$ \\
\hline Chlorpyrifos & $81404 \mathrm{~A}$ & 4450 & $2921-88-2$ \\
Diazinon & $39571 \mathrm{~B}$ & 4451 & $33-41-5$ \\
Dimethoate & $62043 \mathrm{~A}$ & 4452 & $60-51-5$ \\
Disulfonton & $81887 \mathrm{~A}$ & 4453 & $298-04-4$ \\
$\quad$ Disulfonton sulfone & $62048 \mathrm{~A}$ & 4454 & $2497-06-5$ \\
Ethion & $39399 \mathrm{~B}$ & 4455 & $563-12-2$ \\
$\quad$ Ethion monoxon & $62050 \mathrm{~A}$ & 4456 & $17356-42-2$ \\
Ethoprop & $62040 \mathrm{~A}$ & 4457 & $13194-48-4$ \\
$\quad$ O-ethyl-O-methyl-S-propylphosphorothioate* & $62038 \mathrm{~A}$ & 4458 & $76960-87-7$ \\
$\quad$ O-Ethyl-O-meth_ioate] & & & \\
Fenthion & $62046 \mathrm{~A}$ & 4459 & $55-38-9$ \\
Fonofos & $82408 \mathrm{~A}$ & 4460 & $944-22-9$ \\
$\quad$ Fonofos oxygen analog (fonofos oxon) & $62042 \mathrm{~A}$ & 4461 & $944-21-8$ \\
Malathion & $39531 \mathrm{~B}$ & 4462 & $121-75-5$ \\
Methidathion & $62047 \mathrm{~A}$ & 4463 & $950-37-8$ \\
Methyl parathion & $39601 \mathrm{~B}$ & 4464 & $298-00-0$ \\
Parathion & $39541 \mathrm{~B}$ & 4465 & $56-38-2$ \\
Phorate & $81412 \mathrm{~A}$ & 4466 & $298-02-2$ \\
$\quad$ Phorate oxygen analog (phorate oxon) & $62039 \mathrm{~A}$ & 4467 & $2600-69-3$ \\
Profenofos & $62049 \mathrm{~A}$ & 4468 & $41198-08-7$ \\
Propetamphos & $62045 \mathrm{~A}$ & 4469 & $31218-83-4$ \\
Sulfotepp & $62041 \mathrm{~A}$ & 4470 & $3689-24-5$ \\
Sulprofos & $62051 \mathrm{~A}$ & 4471 & $35400-43-2$ \\
Terbufos & $62044 \mathrm{~A}$ & 4472 & $13071-79-9$ \\
Tribufos (DEF or S,S,S-Tributyl phosphorotrithioate) & $39050 \mathrm{~A}$ & 4473 & $78-48-8$ \\
Trithion & $39787 \mathrm{~B}$ & 4474 & $786-19-6$ \\
Isofenfos (surrogate) & $90710 \mathrm{~B}$ & 4475 & $25311-71-1$ \\
\hline & Conp & \\
\hline
\end{tabular}

* Compound marked with an asterisk is permanently reported with an estimated " $E$ " code in this method.

[ ] Name in bracket is an abbreviation used in the National Water Information System because of character number limitation.

( ) Name in parentheses is alternative name of the compound.

NOTE: Letter after parameter code is the method code.

2.5 The extract is evaporated by using nitrogen to a final volume of $0.5 \mu \mathrm{L}$.

2.6 Extracts are determined by dual capillarycolumn GC/FPD with external standard quantitation method.

\section{Safety}

Always observe proper laboratory safety procedures when handling chemicals and operating equipment. Organophosphate compounds, and 
especially the degradates in this method, are recognized potent cholinesterase inhibitors. Liver function can be adversely affected or other health problems can result from prolonged exposure. The method uses substantial volumes of dichloromethane during extraction, which is a suspected carcinogen. All appropriate safety equipment should be worn and extreme care exercised when handling these compounds and solvents. Always wear appropriate clothing, nitrile gloves, and eye protection, and use adequate ventilation when preparing samples or standard solutions. It is important to read the Material Safety Data Sheet (MSDS) on each compound and solvent prior to performing this method. Organic solvents, sediment samples, and rinse wastes should be properly disposed of in accordance with current best available practice.

\section{Interferences}

Sulfur and organosulfur compounds and unknown organophosphorus compounds occasionally might interfere with identification and quantitation of individual organophosphate compounds. There are many organophosphate compounds in natural matrices that GC/FPD will detect, because this procedure involves methylene chloride extraction of sediment samples. This method is designed to minimize false positives through dual GC column confirmation. Mass spectral confirmation may be used to confirm identification if there is uncertainty caused by complex matrix samples.

\section{Collection, Shipment, and Storage of Sediment Samples}

\subsection{Sampling methods and sample-collection} equipment: Use a sampling method that will collect bed-sediment (lake and stream), aqueous suspendedsediment, and soil samples that accurately represent organic contaminant compositions and concentrations at a given location and time. Use sample-collection equipment that is free of plastic tubing, gaskets, and other parts that might leach interferences, absorb contaminants, or abrade and potentially contaminate sediment samples. Detailed descriptions of samplers and sampling methods used to collect representative bed-sediment (lake and stream), aqueous suspendedsediment, and soil samples are contained in the
National Field Manual (U.S. Geological Survey, 1997 to present).

5.2 Cleaning procedures: Wash all samplecollection equipment with phosphate-free detergent, rinse with distilled or tap water to remove all traces of detergent, and finally rinse with methanol (reagent grade or better, ultrapure preferred; dispense methanol by using a Teflon squeeze-bottle) and pesticide-free water. Clean all sample-collection equipment before each sample is collected to prevent crosscontamination of the samples.

5.3 Sample shipment: Ship samples, contained in 1,000-mL wide-mouthed glass jars with lids lined with polytetrafluoroethylene (PTFE) on ice via overnight carrier to the NWQL as soon as possible following collection. Allow sufficient space for expansion of the sample if frozen.

5.4 Sample storage: Following login at the NWQL, samples are stored at $-15^{\circ} \mathrm{C}$ in freezers until time of analysis. Sample holding times for this method have not been established. Holding-time studies in reagent water and on the dry SPE have been performed by Sandstrom and others (2001) for laboratory schedule (LS) 2002 method, which is used to determine most of the compounds present in this method. Recently, Winslow and others (2001) have shown that the addition of chemical preservatives are required to preserve selected organophosphates (OP) and obtain acceptable recoveries in U.S. Environmental Protection Agency (USEPA) method 526 (Winslow and others, 2001), a GC/MS method that uses SPE.

\section{Apparatus and Instrumentation}

The equipment used for this method follows. Specific models and sources that were used for method development also are listed, as appropriate.

6.1 Sample storage, dewatering, and percent moisture determination

6.1.1 Freezer: Upright, capable of storing 100 or more 1,000 -mL wide-mouth jars at $-15^{\circ} \mathrm{C}$ for up to 1 year.

6.1.2 Centrifuge: With four-place rotor, capable of 5,000 relative centrifugal force (rcf), the rpm (revolutions per minute) required to reach 5,000 rcf is equipment specific. International Equipment Co. Model EXD or equivalent.

6.1.3 Centrifuge bottles: 250-mL Teflon (fluorinated ethylene propylene) with sealing cap assemblies and centrifuge bottle adapter. 
6.1.4 Analytical balance: top loading, capable of weighing $250 \pm 0.1 \mathrm{~g}$.

6.1.5 Moisture determination balance: Capable of moisture determination on a 1.8- to 2.2-g aliquot of sediment sample to \pm 0.1 percent moisture, Sartorius Corp., Thermo Control Balance Model YTC O1L or equivalent. volume.

6.1.6 Glass beakers: borosilicate, $400-\mathrm{mL}$

\subsection{Sediment extraction}

6.2.1 Soxhlet apparatus: $85-\mathrm{mL}$ extractor capacity, with 45/50 standard top-taper joint and 24/40 standard bottom-taper joint; fitted with a $500-\mathrm{mL}$ round- or flat-bottom flask with a 24/40 standard taper joint and a water-cooled extractor condenser with $45 / 50$ bottom joint.

6.2.2 Soxhlet extraction sample thimble: borosilicate glass, $35 \times 90 \mathrm{~mm}$, Kontes, Inc., Model K-586500-0022EC or equivalent.

\subsubsection{Soxhlet extraction combined steam} bath/condenser unit: Organomation Associates, Inc. Model 13055 ROT-X-TRACT or equivalent.

6.2.4 Fixed-volume micropipet: 50-, 100-, and $200-\mu \mathrm{L}$ sizes, Drummond micropipetormicrodispenser or equivalent.

\subsection{Sediment extraction concentration}

6.3.1 Kuderna-Danish ( $K-D)$ evaporative concentrator: $500-\mathrm{mL}$ flask, three-ball Snyder column, and a custom-designed 10-mL centrifuge receiver (see 6.3.2), all with 19/22 standard taper joints.

6.3.2 Centrifuge receiver tube: $10-\mathrm{mL}$, made using the top of a $10-\mathrm{mL} \mathrm{K}-\mathrm{D}$ receiver tube, with $19 / 22$ standard female taper joint, fused to an 8-cmlong by $1.6-\mathrm{cm}$ outer diameter centrifuge tube volume graduated at 2, 3, and $5 \mathrm{~mL}$, Allen Scientific Glassblowers, Inc., ASG-215-01 or equivalent.

\subsubsection{Kuderna-Danish combined steam} bath/condenser unit: Organomation Associates, Inc., Model 120 S-EVAP or equivalent.

\subsubsection{Nitrogen manifold sample} concentrator: Organomation Associates, Inc., Model 124 N-EVAP or equivalent.

\subsection{Sediment extract filtration}

6.4.1 Centrifuge: International equipment Co. Model HN-SII or equivalent.

6.4.2 Syringe: 5-mL gas-tight or groundglass syringe equipped with Luer-Lok ${ }^{\mathrm{TM}}$ fitting.

6.5 Gel permeation chromatography
An automated GPC system consists of the following components from Waters Corporation or equivalent:

\subsubsection{High-performance liquid} chromatography (HPLC) pump: Model 501.

6.5.2 Autosampler: Model 717 with 2-mL injection loop capacity with tray storage region maintained at $20^{\circ} \mathrm{C}$.

6.5.3 Absorbance detector: Model 441, with excitation wavelength set at $254 \mathrm{~nm}$.

\subsubsection{Data module and integrator:} Model 746.

6.5.5 Fraction collector: no model number, fitted with a custom tube holder capable of holding 36 , 25-mL K-D receiver tubes.

6.5.6 HPLC in-line precolumn filter unit: Model WATO84560, with replaceable $0.2-\mu \mathrm{m}$ filters.

6.5.7 Column heater: set at $27.0^{\circ} \mathrm{C}$; Jones Chromatography Ltd. or equivalent.

6.5.8 Nitrogen pressurization system: consisting of a regulated grade 5 nitrogen source, PTFE tubing, a 23-gage needle, and associated metal fittings and ferrules for connecting the needle to the nitrogen source via the tubing.

6.5.9 Helium sparging system: used for deoxygenating the dichloromethane solvent prior to GPC.

6.5.10 HPLC pump priming syringe: $25 \mathrm{~mL}$, Hamilton Gas-Tight 1,000 series, Model 82520 or equivalent.

6.5.11 Balance: capable of weighing to 200 $\pm 0.0001 \mathrm{~g}$, Mettler-Toledo Model AT 200 or equivalent.

6.5.12 K-D receiver tube: calibrated $25-\mathrm{mL}$ volume, with 19/22 ground-glass stopper.

6.6 GPC fraction concentration and solvent exchange

6.6.1 Water bath: Precision Scientific Co. Model 82 or equivalent, fitted with a rack capable of holding at least $25-\mathrm{mL}$ receiver tubes.

6.6.2 Micro-Snyder column: three-ball.

6.7 Gas chromatography/flame photometry detection analysis

6.7.1 Gas chromatography: HewlettPackard 5890 Autosystem, equipped with two flame photometry detectors, an autosampler, a split/splitless injector, and a computer controller (Turbochrom instrument control and Target data review software) or equivalent. The GC system must be suitable for use with dual capillary-column GC analysis. 
6.7.2 Syringe: $10-\mu \mathrm{L}$ volume, Hamilton Co. Model 80377 for GC autosampler or equivalent.

6.8 Instrument calibration and spike standards solution preparation

6.8.1 Analytical balance: capable of accurately weighing to $0.0001 \mathrm{~g}$.

6.8.2 Volumetric flasks: varied volumes

from 1 to $1,000 \mathrm{~mL}$.

6.8.3 Micropipets: fixed- and variablevolume pipets from 10 to $250 \mu \mathrm{L}$.

6.8.4 Syringes: variable volumes from 10 to $500 \mu \mathrm{L}$.

\section{Reagents and Consumable Materials}

The following reagents and consumable materials required for this method are grouped by the specific preparation step or analytical procedure. They are not repeated if used in other parts of the method. Specific models and sources that were used for the development or implementation of this method also are listed, as appropriate.

7.1 Sample storage, dewatering, and percent moisture determination

7.1.1 Sample containers: wide mouthed, 1,000 mL, with PTFE-lined lids.

7.1.2 Weighing boats: disposable, aluminum, and $5.1-\mathrm{cm}$ diameter.

7.1.3 Sodium sulfate: anhydrous, granular, reagent grade, bake at $450^{\circ} \mathrm{C}$ for 8 hours and store in a ground-glass stoppered flask in a desiccator until used.

7.2 Sediment extraction

7.2.1 Solvents: dichloromethane and methanol, pesticide grade or ultrapure.

7.2.2 Boiling chips: high purity, amphoteric alundum granule. Four-mesh granule sizes pre-extract with dichloromethane and baked at $450^{\circ} \mathrm{C}$ for 8 hours.

7.2.3 Disposable glass capillaries: to fit the 10-, 25-, 50-, 100-, 200-, and 250- $\mu \mathrm{L}$ fixed-volume micropipets in section 6.8.3. Clean the glass capillaries by baking at $450^{\circ} \mathrm{C}$ for 8 hours.

7.2.4 Surrogate solution: contains isofenfos obtained from Absolute Standards, Inc. or equivalent. Dilute purchased intermediate concentration solutions to a final solution concentration of $1,000 \mathrm{pg} / \mathrm{mL}$ in methanol. Additional surrogates or substitution of surrogates can be made after demonstrating acceptable method performance.

7.2.5 Individual spike solution: contains the individual OP pesticides listed in table 1, obtained from
Absolute Standards, Inc. or equivalent. Dilute an aliquot of each solution into a final spiking solution of $200 \mathrm{pg} / \mu \mathrm{L}$ in methanol.

\subsection{Sediment extract concentration, nitrogen} gas: for solvent evaporation, grade 5 or equivalent.

\subsection{Sample extract filtration}

7.4.1 Filter: $0.2-\mu \mathrm{m}$ pore size, $25-\mathrm{mm}$ diameter disposable PTFE membrane syringe filter, Gelman Sciences Acrodisc ${ }^{\mathrm{TM}}$ CR or equivalent.

7.4.2 Pasteur pipets: baked and clean, both 14.6- and 22.9-cm-long borosilicate disposable pipets with rubber bulbs.

7.4.3 GPC vial, 4- $m L$ : with open-top screwcap and PTFE-faced silicone rubber septum; Supelco Inc., part numbers $2-3219 \mathrm{M}$ and $3-3185 \mathrm{M}$ or equivalent.

\subsection{Gel permeation chromatography}

7.5.1 Helium gas: grade 5 or equivalent.

7.5.2 Gel permeation chromatographic columns: two $30-\mathrm{cm}-$ long by $7.5-\mathrm{mm}$ inside diameter (ID) columns packed with 5- $\mu \mathrm{m}$ diameter styrenedivinylbenzene resin particles having 50-angstrom pore size; Polymer Laboratories, Ltd. PL Gel ${ }^{\mathrm{TM}}$ or equivalent. Connect the columns in series with a low dead-volume union.

\subsubsection{GPC OP fraction test solution:} contains di-n-octyl phthalate, benzo[ghi]perylene, and elemental sulfur, each at a maximum concentration of $250 \mathrm{pg} / \mu \mathrm{L}$ in dichloromethane. Note that the same fraction test solution is used for determining the BNA compounds' collection window; for specific details, refer to Furlong and others (1995). Note that an equivalent $\mathrm{OC}$ (organochlorine) pesticide fraction test solution is used for determining the $\mathrm{OC}$ pesticide collection window when an aliquot of the sample extract is processed for OC pesticides. For specific details, refer to Foreman and others (1995).

7.6 GPC fraction concentration and solvent exchange, ethyl acetate: pesticide-residue grade, or ultrapure.

7.7 Fraction concentration, vial: 1.5 - or $2-\mathrm{mL}$, amber glass, with screw-top caps that have dual PTFEfaced silicon rubber septa.

7.8 Gas chromatography/flame photometry detection analysis

7.8.1 Capillary GC columns

7.8.1.1 Primary column: fused-silica, 30-m by $0.25-\mathrm{mm}$ ID, internally coated with a 5 -percent diphenyl and 95-percent dimethyl-polysiloxane 
stationary phase having a $0.25-\mu \mathrm{m}$ film thickness; Restek Corp. Rtx- $5^{\mathrm{TM}}$ or equivalent.

7.8.1.2 Secondary column: fused-silica, 30$\mathrm{m}$ by $0.25-\mathrm{mm}$ ID, internally coated with a 14 -percent cyanopropylphenyl and 86-percent dimethylpolysiloxane stationary phase having a $0.25-\mu \mathrm{m}$ film thickness; Restek Corp. Rtx-1701 ${ }^{\mathrm{TM}}$ or equivalent.

7.8.2 Column splitter: glass Y-type, Restek Corp. number 20405 or equivalent.

7.8.3 GC guard column: uncoated fusedsilica tubing, $5-\mathrm{m}$ by $0.32-\mathrm{mm}$ ID; Restek Corp. number 10044 or equivalent.

7.8.4 GC injection port liners: glass, borosilicate. Use any instrument-specific splitless or direct injection-port liner that provides acceptable peak shape and detector response.

7.8.5 Silanizing reagent: for deactivating GC injection-port liners; Supelco Inc. Sylon CT or equivalent.

7.9 Solvent for calibration standards: pesticidegrade ethyl acetate, free of specified compounds.

\section{Calibration and Quality-Control Standards and Criteria}

Quality-control information must be evaluated in aggregate to determine whether analytical data are of acceptable quality to be reported. Minimum qualitycontrol requirements include the following: (1) analysis of laboratory reagent sodium sulfate blank; (2) determination of surrogate standard compound recoveries in each sample, blank, and fortified reagent sodium sulfate sample; (3) determination of compound recoveries in the fortified reagent sodium sulfate spike sample; and (4) assessment of the GC/FPD chromatographic performance.

8.1 Calibration standards. Stock standards for the pesticides and degradates were obtained as pure materials (95 percent or higher purity) from the U.S. Environmental Protection Agency (USEPA) National Pesticide Standard Repository (Ft. Meade, Md.) or commercial vendors (ChemService; EQ Laboratories). Prepare calibration standards at six different concentrations $(5,10,20,50,80$, and $100 \mathrm{pg} / \mu \mathrm{L})$ for each compound and surrogate compound by adding a known volume of stock standard solutions to a volumetric flask. Dilute to volume with ethyl acetate. The lowest concentration standard needs to represent compound concentrations near, but greater than, their respective method detection limit (MDL). The remaining standards need to bracket the compound concentrations expected in the sample extracts.

8.2 Calibration curve. Starting with the lowest concentration, analyze each calibration standard and tabulate response (peak area) in relation to the concentration in the standard. This method is an external standard quantitation method, and uses multipoint external standard calibration for singlecomponent compounds. Use the results to prepare a linear calibration curve for each compound. If a linear curve cannot be achieved, especially at low concentrations, then a quadratic curve may be used. For each sample set, analyze all six levels of the calibration standard solutions prior to analyzing the samples. The determined concentration for each compound should be within 20 percent of the expected concentration for all compounds. The correlation coefficient $\left(\mathrm{r}^{2}\right)$ for the linear calibration curve regression should be equal to or greater than 0.995. If the instrument does not meet these calibration criteria, correct the problem by performing GC maintenance or by preparing new calibration standards and reanalyzing the new standards.

8.3 Surrogate standard solution. The surrogate standard solution is prepared from isofenfos available through Absolute Standard, Inc. or equivalent. Surrogate solution is prepared by adding $250 \mu \mathrm{L}$ of isofenfos stock solution ( $100 \mu \mathrm{g} / \mathrm{mL}$ in hexane) into 25 $\mathrm{mL}$ of methanol. The final concentration of isofenfos in methanol is $1 \mathrm{ng} / \mu \mathrm{L}(1,000 \mathrm{pg} / \mu \mathrm{L})$. Add $100 \mu \mathrm{L}$ of the surrogate standard to each field sediment sample, laboratory reagent sodium sulfate spike, and blank samples. Add the surrogate standard solution to the sample at the time of extraction, and use it to monitor performance of the sample preparation procedure (M.R. Burkhardt and T.J. Maloney, U.S. Geological Survey, written commun., 1998). When surrogate recovery for a sample is greater than the upper control limits or less than the lower control limits, check the following: (1) calculations, to locate possible mathematical errors; (2) spike, calibration, and surrogate solutions for degradation; (3) contamination, which usually produces positive bias; and (4) instrument performance (section 8.8). If those steps do not reveal the cause of the problem, reanalyze the extract. If the sample preparation and QC sample criteria do not meet surrogate control limits (M.R. Burkhardt and T.J. Maloney, U.S. Geological Survey, written commun., 1998), then the problem needs to be identified and corrected before continuing analysis. If 
sample extract reanalysis meets the surrogate recovery and other QC criteria, then report data using the reanalyzed extract data. If sample extract continues to fail the recovery criteria, either report all data for that sample as suspect with an estimated ("E"-code) qualifier, raise the reporting level, or do not report the sample data (M.R. Burkhardt and T.J. Maloney, U.S. Geological Survey, written commun., 1998).

8.4 Spiking solution. The laboratory reagent spike (LRS) solution is prepared in methanol by adding $50 \mu \mathrm{L}$ of a mix organophosphate stock solution ( 100 $\mu \mathrm{g} / \mathrm{mL}$ in hexane) into $25 \mathrm{~mL}$ of methanol. This solution contains all of the organophosphate compounds of interest, except the current surrogate compound (isofenfos). The spike solution concentration is $0.2 \mathrm{ng} / \mu \mathrm{L}(200 \mathrm{pg} / \mu \mathrm{L})$, and $1,000 \mu \mathrm{L}$ of this solution is added to $25 \mathrm{~g}$ of reagent sodium sulfate to prepare the LRS. Use the LRS to monitor recovery efficiencies for all method compounds (M.R. Burkhardt and T.J. Maloney, U.S. Geological Survey, written commun., 1998). This report contains spike results for three different concentrations $(8,40$, and 80 $\mu \mathrm{g} / \mathrm{kg}$ ) for the method-performance determinations. The laboratory needs to analyze at least one LRS sample with every 10 samples or one per sample set (all samples extracted within a 24-hour period), whichever is greater. The concentration of each compound in the LRS sample needs to be within the range of the calibration standards. Standard statistical techniques (M.R. Burkhardt and T.J. Maloney, U.S. Geological Survey, written commun., 1998) are used to establish control limits for compound recovery for the LRS. If the recovery of any compound falls outside the control limit criteria, that compound is judged out of control, and the source of the problem needs to be identified and resolved before continuing the analyses. One of three steps can be taken for compounds that fail: (1) report data with estimated ("E") remark code, or (2) increase the reporting level, or (3) do not report the sample data (M.R. Burkhardt and T.J. Maloney, U.S. Geological Survey, written commun., 1998).

8.5 Third-party check standard (TPC). The third-party check standard is commercially available through a vendor, such as Supelco. This solution contains most of the organophosphate compounds of interest, except current surrogate compound (isofenfos). A working TPC is prepared in ethyl acetate by adding $10 \mu \mathrm{L}$ of the TPC stock solution (100 $\mu \mathrm{g} / \mathrm{mL}$ in hexane) to $10 \mathrm{~mL}$ of ethyl acetate. The final working concentration of the TPC is $100 \mathrm{pg} / \mu \mathrm{L}$.
This standard is analyzed in each sequence after the calibration standards to verify the calibration curve. The determined concentration for all compounds in the TPC standard should be within \pm 30 percent of the expected concentration.

8.6 Continuing calibration verification ( $C C V)$ standard. The continuing calibration verification standard concentration is typically at the midpoint of the calibration range, usually a $20-$ or $50-\mathrm{pg} / \mu \mathrm{L}$ organophosphate standard. A CCV containing all of the method compounds is injected after every 10 field or QC samples throughout the GC analytical sequence. This CCV standard is used to monitor the calibration of the GC for bias and variability. The calculated CCV concentration must be within 30 percent of the expected concentration for each compound. If the determined concentrations of compounds in the $\mathrm{CCV}$ are outside the control limits, then the environmental samples are reanalyzed (M.R. Burkhardt and T.J. Maloney, U.S. Geological Survey, written commun., 1998).

8.7 Laboratory reagent blank ( $L R B)$. Before processing any samples, the analyst must demonstrate that all glassware and reagent interferences are under control. Each time a set of samples is extracted or reagents are changed, a laboratory reagent blank (LRB) sample (contains sodium sulfate) needs to be analyzed. If the LRB contains interfering peaks that would prevent the determination of one or more compounds, then determine the source of contamination and eliminate the interferences before continuing sample processing and analysis. If the interferences cannot be eliminated, then qualify the data (M.R. Burkhardt and T.J. Maloney, U.S. Geological Survey, written commun., 1998).

8.8 Instrument system. Instrument performance needs to be monitored daily. Gas chromatographic performance normally is reflected in the variation of determined concentration of the selected compound in calibration standards, TPC, and CCV relative to the concentrations obtained by using a new capillary column and freshly prepared standards. Corrective actions for failure to meet the calibration, TPC, or CCV criteria not attributed to other causes indicate that the GC system might need maintenance. For example, part of the guard column might be cut off and removed to restore performance, or the injection port liner might be replaced.

8.9 Other GC/FPD performance requirements. Sample concentrations that exceed the high 
concentration calibration curve must be diluted to within the calibration range and reanalyzed. Additional quality-control practices can be used with this method (see Pirkey and Glodt, 1998).

\section{Sample Preparation Procedure}

Samples are grouped into sets of 16 total samples, including QC samples, because two extraction units accommodate up to 16 samples. Typically, 12 field samples are included in a set; the remaining positions in the set are filled with laboratory QC samples.

9.1 Sample dewatering and percent moisture determination

thaw.

9.1.1 Retrieve samples from the freezer and

9.1.2 Thoroughly homogenize each sample with a stainless steel spatula.

9.1.3 Remove about a 20-g wet-weight aliquot to an appropriate container for separate determination of total carbon and total inorganic carbon (Wershaw and others, 1987). Total organic carbon is obtained by difference.

9.1.4 Weigh about $150 \pm 0.1 \mathrm{~g}$ of homogenized sample into a tared $250-\mathrm{mL}$ centrifuge bottle and record sediment weight (Wa). Up to four samples can be processed at a time. If there is an odd number of samples, counterbalance the centrifuge by placing a tube with water plus cap that weighs 150 $\pm 0.1 \mathrm{~g}$. The centrifuge is operated at $2,000 \mathrm{rpm}$ for 20 minutes. Carefully decant the clear supernatant water; pipet the supernatant using a Pasteur pipet if the sediment pellet is too soft. If the supernatant is not clear, repeat centrifugation before decanting. Record weights of sediment after decanting water $(W b)$.

NOTE: For safety, the centrifuge must be balanced prior to operation.

9.1.5 Thoroughly re-homogenize the sediment sample in the centrifuge bottle. Remove a 1.8- to 2.2-g aliquot of sediment and determine the moisture content of the centrifuged sediment to \pm 0.1 percent using the moisture determination balance (6.1.5). The wet-weight fraction ( $f w$ ) of the centrifuged sediment $=$ percent wet weight $/ 100$.

Calculate the dry-weight fraction of centrifuged sediment $(f d)$ :

$$
f d=1-f w
$$

9.1.6 Weigh an amount of wet, centrifuged sediment needed to produce a 25 -g equivalent dryweight sample into a tared $400-\mathrm{mL}$ beaker. Weight of wet sediment needed for extraction $=25 \mathrm{~g} / f d$. Record sediment wet weight $(W w)$ to $\pm 0.1 \mathrm{~g}$.

9.1.7 Add anhydrous sodium sulfate to the beaker in an amount equivalent to about four times the amount of water present in the sediment. The total amount of sediment-sodium sulfate mixture must not exceed $160 \mathrm{~g}$, otherwise the mixture will not fit completely within an extraction thimble (larger thimble may be used if needed for each $25 \mathrm{~g}$ of sample) (see 9.2.1):

Weight of sodium sulfate needed $=W w \times f w \times 4$

where

$$
\begin{aligned}
& W w=\text { wet-sediment weight, in grams (9.1.6); and } \\
& f w=\text { wet-weight fraction of sediment (9.1.5). }
\end{aligned}
$$

Mix thoroughly, and, if necessary, add more sodium sulfate to ensure that the mixture is dry and loose.

NOTE: The sodium sulfate/sample mixture needs to be porous for efficient Soxhlet extraction.

\subsection{Sediment extraction}

9.2.1 Add the sediment-sodium sulfate mixture to a Soxhlet extraction thimble. Repeat for all samples.

9.2.2 Prepare the following QC samples as required, depending on the types of analyses to be performed.

9.2.2.1 Laboratory blank (set blank): Place $125 \mathrm{~g}$ of sodium sulfate into an extraction thimble.

9.2.2.2 Reagent OP spike sample (set spike): Place $125 \mathrm{~g}$ sodium sulfate into an extraction thimble, place thimble into Soxhlet, and spike sodium sulfate with $1 \mathrm{~mL}$ of individual OP spike solution.

9.2.3 Extract and process the QC samples through the remainder of the method exactly as for the field-sediment samples.

9.2.4 Place the extraction thimble into a Soxhlet apparatus connected to a 500 -mL flask containing $350 \mathrm{~mL}$ dichloromethane and 5 to 10 boiling chips.

9.2.5 Add $100 \mu \mathrm{L}$ of OP surrogate solution (7.2.4) on top of each sample contained in a thimble using a micropipet. 
9.2.6 Carefully add $25 \mathrm{~mL}$ methanol to the top of the sample and allow 20 minutes for the solvent to percolate through sample to the thimble frit. This step helps to remove any residual moisture not bound by the sodium sulfate.

NOTE: Do not use more than $25 \mathrm{~mL}$ of methanol during this step. The amount of methanol added must not exceed 7 percent of the total volume of dichloromethane plus methanol used during the extraction (see note 9.3.2).

9.2.7 Attach the Soxhlet apparatus to the condenser and extract the sample at $70^{\circ} \mathrm{C}$ for at least 12 hours.

9.2.8 Following extraction, add about $50 \mathrm{~g}$ of sodium sulfate to the flask and swirl to remove residual water. Add additional sodium sulfate as needed to ensure water removal. Excessive amounts of water might require separation using a 1-L separatory funnel. Seal with a ground-glass stopper and store sodium sulfate-containing extract in a refrigerator at $4^{\circ} \mathrm{C}$ for at least 4 hours.

\subsection{Sediment extract concentration}

9.3.1 Transfer the extract (but not the sodium sulfate) from the flask to a K-D concentrator (6.3.1) fitted with a $10-\mathrm{mL}$ centrifuge receiver tube (6.3.2) containing boiling chips. Rinse the flask three times using 5- to $10-\mathrm{mL}$ aliquots of dichloromethane and transfer these rinses to the K-D concentrator.

\subsubsection{Concentrate the extract to about 4 to 6} $\mathrm{mL}$ at $70^{\circ} \mathrm{C}$.

NOTE: The methanol used in the extraction step must be removed during this K-D concentration step, otherwise it will cause problems during the GPC cleanup (9.5). Methanol is completely removed only by the formation of an azeotrope having a 92.7-percent dichloromethane and 7.3-percent methanol composition that boils at $37.8^{\circ} \mathrm{C}$ (at $101.3 \mathrm{kPa}$ ). Therefore, the amount of methanol must not exceed 7 percent of the total extract volume of dichloromethane plus methanol in the Soxhlet extract (9.3.1); otherwise the desired azeotrope composition will not take place during the K-D concentration (see 9.2.6 NOTE).

9.3.3 Further reduce the extract to $3.0 \mathrm{~mL}$ using a gentle stream of nitrogen gas (6.3.4). Store extract in a refrigerator or freezer until step 9.4.

\subsection{Sediment extract filtration}

9.4.1 Place paired sets of extracts contained in uncapped centrifuge receiver tubes into a centrifuge (6.4.1) and centrifuge at $2,150 \mathrm{rpm}$ for 10 minutes.
9.4.2 Tare a labeled, 4-mL GPC vial with cap and septum attached (7.4.3) to $\pm 0.0001 \mathrm{~g}$.

9.4.3 Attach a 0.2- $\mu \mathrm{m}$ PTFE filter to a 5-mL Luer-Lok syringe. Remove the syringe plunger and place a tarred GPC vial under filter-tip outlet.

9.4.4 Transfer the centrifuged extract to the syringe barrel using a Pasteur pipet, taking care not to dislodge the centrifuged solids.

9.4.5 Carefully insert the plunger into the syringe and pass the extract through the filter into the GPC vial. After expelling sample, push air through the filter to remove residual extract from the filter.

9.4.6 Rinse the centrifuge receiver tube with $500 \mu \mathrm{L}$ dichloromethane, washing down the tube walls with the Pasteur pipet. Transfer the rinse (including centrifuged solids) to the syringe barrel using the Pasteur pipet. Filter this rinse into GPC vial as in 9.4.5.

9.4.7 Repeat step 9.4.6.

9.4.8 Bring extract volume up to $4 \mathrm{~mL}$ with dichloromethane and cap GPC vial. Store extract in a refrigerator or freezer until step 9.5.

\subsection{Gel permeation chromatography}

Complete details of GPC operation are beyond the scope of this report. Instead, the following procedure outlines the steps necessary for GPC instrument fraction calibration and subsequent cleanup of sample extracts. Consult the appropriate instrument manuals for additional details regarding general GPC system operation and NWQL standard operating procedure MS0024.0 (or subsequent revisions; available upon request) for detailed, method-specific GPC procedures.

9.5.1 The GPC data system should remain turned on continuously to maintain integrity. Other system components, including the pump, autosampler, detector, fraction collector, and column heater, should be turned on at least 2 hours in advance of fraction calibration.

9.5.2 Degas the dichloromethane mobile phase with helium for 30 minutes prior to use.

9.5.3 Pump degassed dichloromethane through the GPC columns at the mobile phase flow rate of $1 \mathrm{~mL} / \mathrm{min}$ for at least 2 hours prior to fraction calibration (9.5.8).

NOTE: Slowly ramp up the flow rate from 0.1 to 1 $\mathrm{mL} / \mathrm{min}$ over a 1 -minute period to minimize pressure shock to the GPC columns.

9.5.4 Bring the GPC vial containing the sample to room temperature.

9.5.5 Just prior to vial pressurization (see section 9.5 .6 below), weigh the extract contained in the 
tared GPC vial with cap and septum to $\pm 0.0001 \mathrm{~g}$ and record extract weight [Wt. Extract Before GPC $=\mathrm{Wt}$. Extract and Vial Before GPC (9.5.5) minus the Vial Tare Wt. (9.4.2)]. Similarly, weigh GPC vials (with cap and septum) after injection. The fraction of the sample injected into the GPC system will be determined by weight difference before and after GPC injection.

9.5.6 For all samples, the GPC vial headspace is pressurized with nitrogen gas just prior to beginning a GPC fractionation sequence. This pressurization assists the syringe in withdrawing the correct aliquot of extract or solution for injection into the GPC. Pierce the vial septum with the pressurization needle, and pressurize with $207 \mathrm{kPa}$ nitrogen for about 1 minute. Make sure the end of needle is not placed into the liquid. Rinse the needle with clean dichloromethane between pressurization of each vial.

9.5.7 Establish GPC system cleanliness and baseline stability by injecting a $1,400-\mu \mathrm{L}$ aliquot of clean pesticide-grade dichloromethane (System Blank) and monitoring detector response at low attenuation (usually at attenuation 8). Fractions typically are not collected for GPC System Blank analyses.

9.5.8 GPC fraction calibration: Elution times might vary between analyses of sample set because of GPC column aging, the presence of residual methanol from sample extraction, and other factors. Therefore, prior to beginning automated analysis, the fraction collection beginning and end times are established for the OPs to allow final configuration of the fraction collector.

9.5.8.1 Establish OP fraction collection times by injecting $1,400 \mu \mathrm{L}$ of the GPC-OP fraction test solution (7.5.3) and monitoring the elution times of the peaks at low attenuation. Repeat injections of the GPC-OP fraction test solution as necessary to ensure chromatographic reproducibility. Fractions are not collected for the GPC-OP fraction calibration test analyses.

\subsubsection{A typical GPC chromatogram} resulting from analysis of the GPC-OP fraction test solution is shown in figure 1. Set the "beginning time" on the fraction collector at the time when the detector baseline begins to rise for the di-n-octylphthalate peak. The beginning time is determined by processing the chromatogram resulting from the injection of the

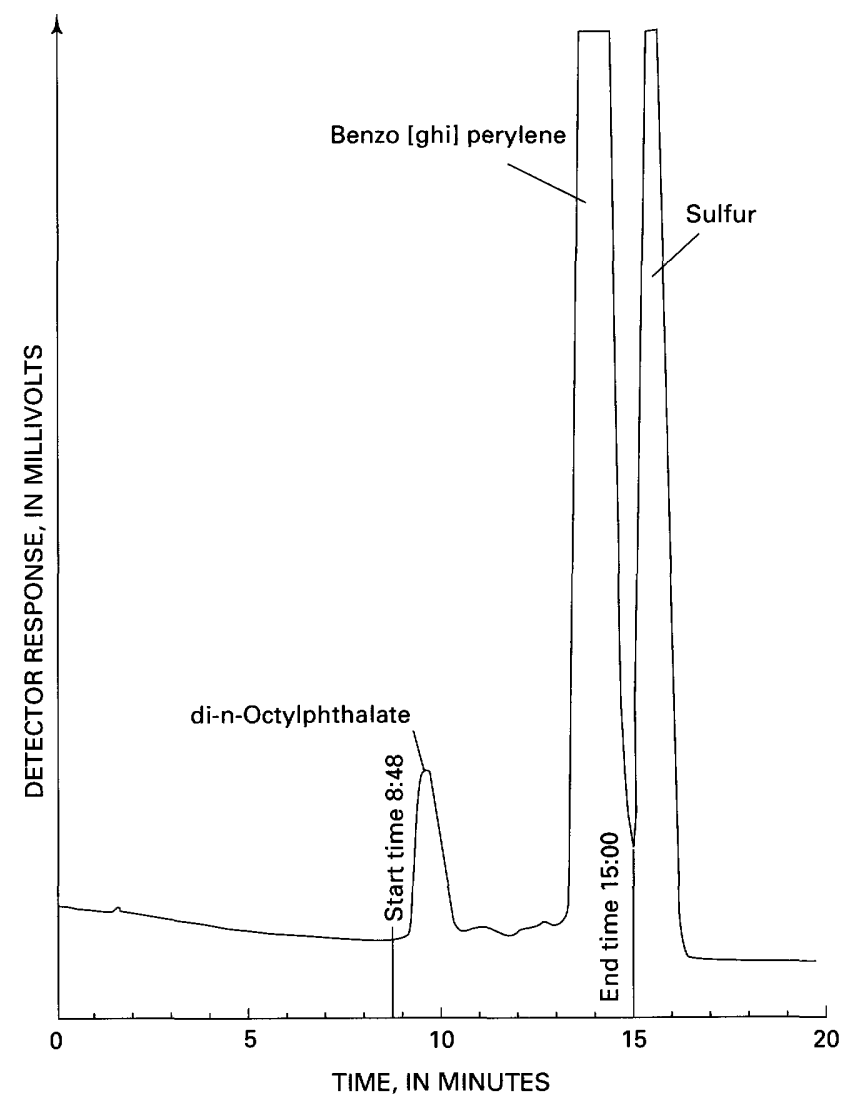

Figure 1. Gel permeation chromatogram of the fraction test solution at attenuation 8 showing analyst-determined start and end times for the organophosphate pesticide fraction. Chromatographic conditions are given in text.

GPC-OP fraction test solution at attenuation 8 and graphically determining when the baseline begins to rise, thus indicating the first peak.

9.5.8.3 Set the "end time" on the fraction collector for the GPC-OP fraction at the valley between the benzo[ghi]perylene peak and the sulfur peak.

9.5.9 Perform a GPC automated separation. Inject $1,400 \mu \mathrm{L}$ of the sample extract and collect the GPC-OP fraction in a 25-mL K-D receiver tube. Each sample is analyzed on the GPC for 30 minutes. The fraction collected is determined by the GPC calibration window solution, which is analyzed prior to each set. A suggested processing sequence, using the sample types contained in a normal sample set at the NWQL (one set blank, set OP spike, and 12 field samples), is listed in table 2. Repeated injections of the GPC-OP fraction test solution and the System Blanks help to ensure continued calibration and system cleanliness. 
Table 2. Suggested gel permeation chromatography processing sequence

$[O P$, organophosphate pesticide; GPC, gel permeation chromatography]

\begin{tabular}{|c|c|}
\hline $\begin{array}{l}\text { Analytical } \\
\text { sequence }\end{array}$ & Sample type \\
\hline 1 & System blank \\
\hline 2 & Set blank \\
\hline 3 & Set OP spike (or set spike options) \\
\hline 4 & Sample 1 \\
\hline 5 & Sample 2 \\
\hline 6 & Sample 3 \\
\hline 7 & Sample 4 \\
\hline 8 & Sample 5 \\
\hline 9 & Sample 6 \\
\hline 10 & Sample 7 \\
\hline 11 & Sample 8 \\
\hline 12 & GPC-OP fraction test solution \\
\hline 13 & System blank \\
\hline 14 & Sample 9 \\
\hline 15 & Sample 10 \\
\hline 16 & Sample 11 \\
\hline 17 & Sample 12 \\
\hline 18 & GPC-OP fraction test solution \\
\hline 19 & System blank \\
\hline 20 & 2-chlorobutane solvent wash \\
\hline 21 & 2-chlorobutane solvent wash \\
\hline 22 & 2-chlorobutane solvent wash \\
\hline 23 & System blank \\
\hline
\end{tabular}

9.5.10 Reweigh the GPC sample vial with original cap and septum to $\pm 0.0001 \mathrm{~g}$ as soon as possible after injection of the sample or following completion of automated separation. [Wt. of OP Extract GPC'd = Wt. of OP Extract and vial before GPC (9.5.5) minus Wt. of OP Extract and vial after GPC.]

9.5.11 Cap K-D receiver tube containing the GPC-OP fraction with a ground-glass stopper and store in a refrigerator until the concentration step (9.6).

9.5.12 Replace the septum on the GPC sample vial and store the remaining portion of the extract not processed through the GPC in a freezer for subsequent GPC injection or reanalysis of OP fraction, if needed.

9.6 GPC-OP fraction concentration and solvent exchange

9.6.1 Add $4 \mathrm{~mL}$ of ethyl acetate and two to three small boiling chips to the extract and attach a three-ball micro-Snyder column to the top of the K-D receiver tube.
9.6.2 Slowly introduce the K-D receiver tube to a water bath $(6.6 .1)$ maintained at $70^{\circ} \mathrm{C}$ and reduce the solvent volume to about $4 \mathrm{~mL}$ or until solvent evaporation dramatically decreases. Remove the tube from bath and cool.

9.6.3 Raise bath temperature from 70 to 85 to $87^{\circ} \mathrm{C}$. Add two to three fresh boiling chips and $1 \mathrm{~mL}$ ethyl acetate to the K-D receiver tube, vortex, and replace into water bath for about 20 minutes. Do not reduce solvent volume to less than $1 \mathrm{~mL}$.

9.6.4 Remove tube from water bath and reduce the extract to $0.5 \mathrm{~mL}$ using a gentle stream of nitrogen (6.3.4).

9.6.5 Transfer the fraction to a $1.8-\mathrm{mL}$ autosampler vial using a Pasteur pipet and cap the vial mixture. Store in a refrigerator at $4^{\circ} \mathrm{C}$ until analysis by GC/FPD.

\section{Gas Chromatography/Flame Photometric Detection Analysis}

10.1 Analyze the sample extracts by gas chromatography with flame photometric detection (GC/FPD) using a dual capillary-column system (6.7.1) equipped with an autosampler; one split/ splitless injection port (operated in the splitless mode); a 5-m, 0.32-mm ID section of fused-silica capillary tubing, uncoated, deactivated guard column (7.8.3); a Y-type column splitter (7.8.2) to connect the guard column to the primary (7.8.1.1) and secondary (7.8.1.2) capillary columns; and two flame photometric detectors. Use a computer system to control the autosampler, gas chromatograph (GC) operational conditions, and to acquire and process responses from the dual detectors. Complete details of GC/FPD operation are beyond the scope of this report. The following procedure outlines the suggested GC conditions and autosequence used in this method. Consult the appropriate instrument manuals for additional details regarding general GC/FPD system operation.

\subsection{Suggested GC operational conditions} NOTE: Use any operational conditions that provide acceptable levels of compound separation, identification, quantitation, accuracy, and precision.

Carrier gas-Helium, 99.999 percent purity, 1 to $3 \mathrm{~mL} / \mathrm{min}$ column flow. This flow range corresponds to a linear flow velocity of 20 to $40 \mathrm{~cm} / \mathrm{sec}$ on the Van Deemter plot, when using $30-\mathrm{m}$ by $0.25-\mathrm{mm}$ ID columns. 
Detector make-up gas-Nitrogen, 99.999 percent purity, 4 to $10 \mathrm{~mL} / \mathrm{min}$ flow.

Detector gas - Hydrogen, 99.999 percent purity, 3 to $5 \mathrm{~mL} / \mathrm{min}$ flow.

Air-99.6 percent purity, 90 to $110 \mathrm{~mL} / \mathrm{min}$ flow.

Injection mode-Splitless, injection port sweep 30 $\mathrm{mL} / \mathrm{min}$. Column head pressure $138 \mathrm{kPa}\left(20 \mathrm{lb} / \mathrm{in}^{2}\right)$. Septum purge flow is 1 to $2 \mu \mathrm{L} / \mathrm{min}$. Split purge valve is turned on (open) at 2 minutes and off (closed) 2 minutes prior to end of sample analysis. Both columns are connected to guard column using " $Y$ " splitter, and the guard column is connected to injection port. If flows through the GC columns are equivalent, then an injection volume of $4 \mu \mathrm{L}$ of extract is divided evenly onto both columns. Dual columns are used to verify the compound detection.

Injector temperature $-220^{\circ} \mathrm{C}$.

Detector temperature $-220^{\circ} \mathrm{C}$.

Detectors - Two flame photometric detectors (FPD), set for "P" mode, with optical filters that transmit 525-nm wavelength for specific phosphorus response.

Oven temperature program - Initial temperature $60^{\circ} \mathrm{C}$, hold 1 minute.

Ramp $1-15^{\circ} \mathrm{C} / \mathrm{min}$ to $160^{\circ} \mathrm{C}$, hold 0 minute.

Ramp $2-1^{\circ} \mathrm{C} / \mathrm{min}$ to $186^{\circ} \mathrm{C}$, hold 0 minute.

Ramp $3-7^{\circ} \mathrm{C} / \mathrm{min}$ to $280^{\circ} \mathrm{C}$, hold for 7 minutes.

Total analysis time is about 54 minutes.

10.3 Determine compound retention times (RT) - Following GC setup, establish compound retention times using the calibration standard solutions. A typical chromatographic separation and the resulting peak shape obtained using the GC operating conditions in section 10.2 are shown in figure 2 for the individual OP pesticides on the Rtx-5 column; separation and peak shape on the Rtx-1701 column are shown in figure 3. Peak identifications and retention times for the method compounds on the Rtx-5 and Rtx-1701 columns that are shown in figures 2 and 3 are listed in table 3 .

10.4 Coelution problems - Using the GC conditions described in 10.2, two coelutions (one for fonofos with propetamphos and a second for fenthion, chlorpyrifos, and parathion) were observed on the Rtx5 column and three coelutions (one for chlorpyrifos with methyl parathion, the second for methidathion with profenophos, and a third for disulfoton sulfone, ethion, and sulprofos) most commonly were observed on Rtx-1701 column. Compounds that have coelutions on one column are well separated from other method
Table 3. Retention times of method compounds on the Rtx-5 and Rtx-1701 columns

[Compounds are listed in Rtx-5 retention time order]

\begin{tabular}{|c|c|c|}
\hline \multirow[t]{2}{*}{ Compound } & \multicolumn{2}{|c|}{$\begin{array}{l}\text { Retention time } \\
\text { (minutes) }\end{array}$} \\
\hline & Rtx-5 & Rtx-1701 \\
\hline O-ethyl-O-meth_ioate & 8.99 & 9.23 \\
\hline Phorate oxon & 14.37 & 17.21 \\
\hline Ethoprop & 14.81 & 16.80 \\
\hline Sulfotepp & 16.37 & 19.21 \\
\hline Phorate & 16.68 & 18.75 \\
\hline Fonofos oxon & 16.88 & 20.48 \\
\hline Dimethoate & 18.03 & 28.39 \\
\hline Terbufos & 19.65 & 21.84 \\
\hline Fonofos & $19.85^{\mathrm{a}}$ & 22.81 \\
\hline Propetamphos & $19.96^{\mathrm{a}}$ & 25.40 \\
\hline Diazinon & 20.77 & 22.57 \\
\hline Disulfonton & 21.04 & 24.20 \\
\hline Methyl parathion & 25.05 & $33.96^{\mathrm{e}}$ \\
\hline Malathion & 29.47 & 36.31 \\
\hline Fenthion & $30.23^{b}$ & 35.71 \\
\hline Chlorpyrifos & $30.40^{\mathrm{b}}$ & $33.85^{\mathrm{e}}$ \\
\hline Parathion & $30.52^{b}$ & 37.76 \\
\hline Isofenfos (surrogate) & 35.37 & 39.00 \\
\hline Methidathion & 36.68 & $41.01^{\mathrm{d}}$ \\
\hline Disulfonton sulfone & 37.61 & $43.67^{\mathrm{c}}$ \\
\hline Profenofos & 38.93 & $41.21^{\mathrm{d}}$ \\
\hline Tribufos & 39.15 & 40.49 \\
\hline Ethion monoxon & 39.97 & 43.15 \\
\hline Ethion & 41.72 & $43.79^{c}$ \\
\hline Sulprofos & 42.23 & $43.87^{\mathrm{c}}$ \\
\hline Trithion & 42.60 & 44.24 \\
\hline
\end{tabular}

${ }^{\mathrm{a} C}$ Coelutions on Rtx-5, well separated on Rtx-1701.

${ }^{\mathrm{b} C}$ Coelutions on Rtx-5, well separated on Rtx-1701.

${ }^{\mathrm{c} C}$ Coelutions on Rtx-1701, well separated on Rtx-5.

${ }^{\mathrm{d}}$ Coelutions on Rtx-1701, well separated on Rtx-5.

${ }^{\mathrm{e}}$ Coelutions on Rtx-1701, well separated on Rtx-5.

compounds on the other column (see table 3 ).

Coelution conditions require special identification and calibration considerations. Compounds that show coelution with another method compound on one column must be quantified on the column where no coelution problem results. 


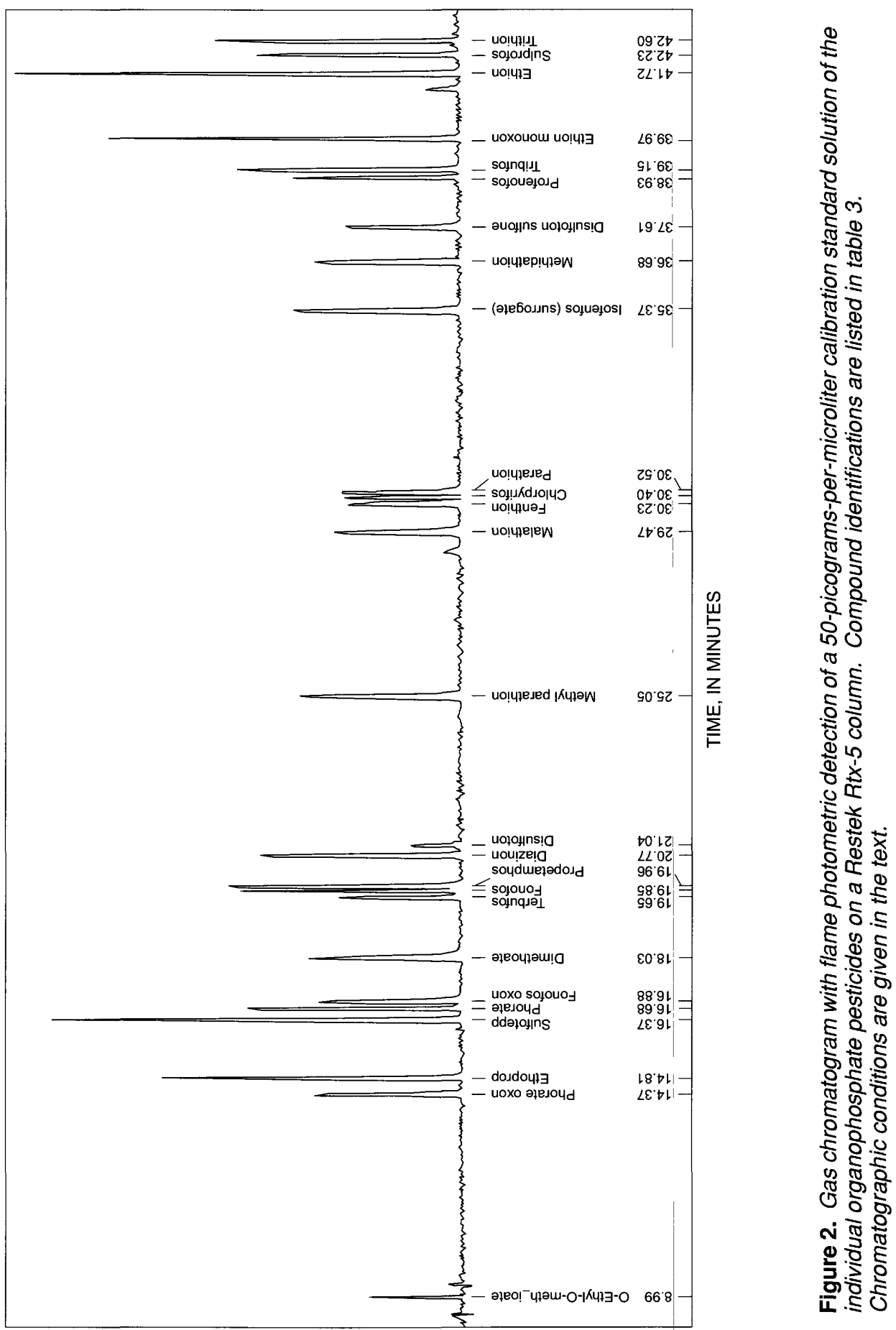




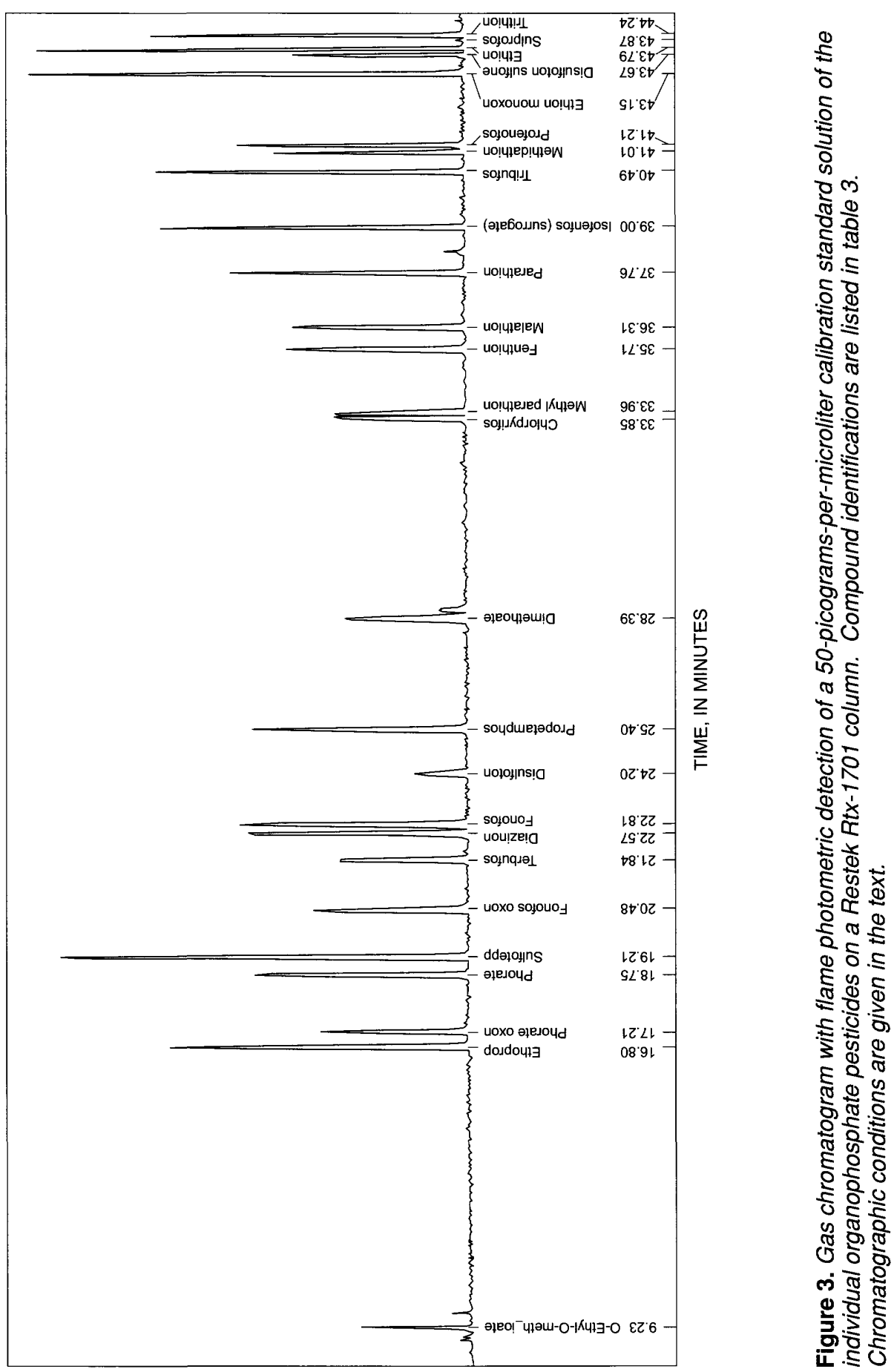


10.5 GC autosequence-The recommended sequence for an automated analysis is listed in table 4 .

Table 4. Suggested gas chromatography/flame photometric detection autosequence

[pg/ $\mu L$, picogram per microliter]

\section{Standard or sample type \\ (with paragraph number)}

Ethyl acetate gas chromatograph injection blank

Calibration standard $5 \mathrm{pg} / \mu \mathrm{L}(8.1)$

Calibration standard $10 \mathrm{pg} / \mu \mathrm{L}(8.1)$

Calibration standard $20 \mathrm{pg} / \mu \mathrm{L}(8.1)$

Calibration standard $50 \mathrm{pg} / \mu \mathrm{L}(8.1)$

Calibration standard $80 \mathrm{pg} / \mu \mathrm{L}(8.1)$

Calibration standard $100 \mathrm{pg} / \mu \mathrm{L}(8.1)$

Third-party check solution (8.5)

Laboratory blank (LRB) 9.2.2.1)

Reagent organophosphate spike sample (LRS) 9.2.2.2)

Continuing calibration verification (CCV) standard (8.6)

Ten field samples

$\mathrm{CCV}$

Ten field samples

$\mathrm{CCV}$

\subsection{Gas chromatography/flame photometric} detection compound calibration-This method is an external standard quantitation method and uses multipoint external standard calibration for singlecomponent compounds. The GC/FPD is calibrated (and compounds subsequently quantitated; see section 11) by using results obtained on both capillary columns. The individual OP pesticides can be calibrated by using multipoint curves produced from analysis of the 5- to $100-\mathrm{pg} / \mu \mathrm{L}$ calibration standard solutions (8.1). Plot the GC/FPD peak area for the compound $\left(A_{c}\right)$ in relation to the mass (in picograms) of the compound for each of the 5- to $100-\mathrm{pg} / \mu \mathrm{L}$ calibration standards injected. Calculate a calibration curve for this plot using the simple linear regression model of the form $\{Y=m \times X+b$; where $X=$ $\left.\left(C_{c} \times V_{1}\right)\right\}$

$$
A_{c}=m \times\left(C_{c} \times V_{1}\right)+b
$$

where

$$
\begin{gathered}
m=\text { compound-specific slope, in area per } \\
\text { picogram; } \\
C_{c}=\begin{array}{l}
\text { concentration of the compound in the } \\
\text { standard solutions, in picograms per } \\
\text { microliters; }
\end{array}
\end{gathered}
$$

$V_{1}=$ volume of calibration standard solutions injected into GC/FPD, in microliters; and

$b=$ compound-specific $Y$-intercept of the best-fit linear regression line.

\section{Calculation of Results}

11.1 Calculate the dry weight of sediment extracted, in grams $\left(W_{s}\right)$ :

$$
W_{s}=W_{w} \times f d
$$

where

$$
\begin{aligned}
& W_{w}=\text { wet weight of sediment, in grams (9.1.6); } \\
& \quad \text { and }
\end{aligned}
$$

11.2 Calculate the concentration of compounds in the sample:

Use the compound-specific regression parameters $m$ and $b$ (equation 3 ) from the calibration curve to calculate the peak area response ( $R A$, in picograms per microliter) of compound in the analyzed sample extract using

$$
R A=\frac{\left(A_{s}-b\right)}{m \times V_{2}}
$$

where

$$
\begin{gathered}
A_{s}=\text { the peak area of the identified compound } \\
\text { in the sample extract; and } \\
V_{2}=\text { volume of extract injected into GC/FPD, } \\
\text { in microliters }(10.2) .
\end{gathered}
$$

11.3 Calculate the concentration $\left(C_{s}\right)$ of the identified compound in the sample, in microgram per kilogram in dry-weight sediment, using:

$$
C_{s}=\frac{R A \times V E \times\left(W_{1} / W_{2}\right)}{W_{s}}
$$


where

$C_{S}=$ concentration of compound in sample, in micrograms per kilogram (equivalent to nanograms per gram);

$R A=$ peak area of compound, in nanograms per milliliter (equivalent to picograms per microliter, calculated from equation 5);

$V E=$ volume of sample extract just prior to $\mathrm{GC} / \mathrm{FPD}$, in milliliters (9.6.4);

$W_{1}=$ weight of sample extract before GPC, in grams (9.5.5);

$W_{2}=$ weight of sample extract processed through the GPC, in grams (9.5.10); and

$W_{s}=$ dry weight of sample extracted, in grams (calculated from equation 4).

11.4 Calculate the percent recovery of the surrogate compounds in each sample using:

$$
R_{a}=\left[\frac{C_{s}}{\left(C_{a} \times V_{a}\right) / W_{s}}\right] \times 100
$$

where

$$
\begin{aligned}
& R_{a}=\text { recovery of surrogate in sample, in percent; } \\
& C_{s}=\text { determined concentration of surrogate in }
\end{aligned}
$$

11.5 Calculate the percent recovery of compounds in reagent $\mathrm{OP}$ spike sample using:

$$
R_{b}=\left[\frac{C_{s}}{\left(C_{b} \times V_{b}\right) / W_{s}}\right] \times 100
$$

where

$R_{b}=$ recovery of spiked compound in the reagent $\mathrm{OP}$ spike sample, in percent;
$C_{s}=$ determined concentration of compound in reagent $O P$ spike sample, in nanograms per gram (calculated from equation 6);

$C_{b}=$ concentration of compound in OP spike solution added to sample, in nanograms per microliter (7.2.5);

$V_{b}=$ Volume of OP spike solution added to the sample, in microliters (9.2.2.2); and

$W_{s}=$ specified method dry weight of sample, in grams $(25 \mathrm{~g})$.

NOTE: The actual (or assumed) sample weight $\left(W_{s}\right)$ of the matrix used for preparing the reagent spike sample must be equivalent in equations 6 and 8 .

11.6 Calculate the percent moisture of the uncentrifuged sediment (9.1.4) using:

Percent moisture in uncentrifuged sediment $=$

$$
\frac{\left(W_{a}-W_{b}\right)+W_{b}\left(f_{w}\right)}{W_{a}} \times 100
$$

where

$$
\begin{gathered}
W_{a}=\begin{array}{c}
\text { weight of sample-water mixture prior to } \\
\text { centrifugation, in grams (from 9.1.4); }
\end{array} \\
\begin{array}{c}
W_{b}=\text { weight of centrifuged sample-water mixture } \\
\text { after decanting water, in grams (from } \\
9.1 .4 \text { ); and }
\end{array} \\
f_{w}=\begin{array}{c}
\text { wet-weight fraction of centrifuged and } \\
\text { decanted sediment, calculated by } \\
\text { dividing the percent moisture content } \\
\text { (9.1.5) by } 100 .
\end{array}
\end{gathered}
$$

NOTE: The percent moisture of the uncentrifuged sediment is not required to calculate the compound concentrations in micrograms per kilogram dry-weight sediment. Users can calculate the percent moisture value of the compound concentrations in micrograms per kilogram wet-weight sediment for comparison with historical data that are normalized to wet weight of sediment. The percent moisture of the uncentrifuged sediment calculated in equation 9 does not include any water decanted from the sediment sample prior to sample freezing for storage (5.4). Concentrations normalized to dry weight are more accurate than those normalized to wet weight because of the highly variable amounts of water used to process sediment samples on site. 


\section{Reporting of Results}

\subsection{Column-dependent quantitation-The} quantitative value reported is column dependent. Report the lower concentration produced by the two GC columns unless it has been demonstrated by the calibration, $\mathrm{CCV}$, or TPC standards that one of the columns is causing a method compound to degrade or otherwise produce errant results. Column-specific quantitation also will be necessary for those compounds that exhibit coelution or other apparent interference on one GC column.

\subsection{Reporting units-Report compound} concentrations for field samples in micrograms per kilogram $(\mu \mathrm{g} / \mathrm{kg})$ dry sediment. If the concentration is less than the lowest calibration standard, report the concentration to two significant figures, and use the "E" code to indicate that the concentration has been estimated. If the concentration is greater than the highest calibration standard, dilute the sample appropriately to bring the concentration within calibration range (generally the midpoint) and report the concentration to three significant figures. Report surrogate data for each sample type as percent recovered. Report data for the set spike samples as percent recovered. Compounds quantified in the set blank samples are reported in micrograms per kilogram, assuming a 25-g dry-sample weight. Report compound concentrations for field samples to three significant figures. Report surrogate data for each sample type to three significant figures.

12.3 Reporting limits-Estimates of method detection limits (MDLs) using the procedures outlined by the U.S. Environmental Protection Agency (1997) have been performed for this method and are discussed further in 13.7 and in table 6 . The initial laboratory reporting levels (LRL) for this method are listed in table 5, and were calculated by using the long-term method detection levels described by Childress and others (1999).

\section{Method Performance}

13.1 Reagent-sodium sulfate, a sediment sample collected from Evergreen Lake, Evergreen, Colorado, and a sediment sample collected from the Clear Creek near Central City, Colorado, were used to test method performance.
Table 5. Initial laboratory reporting levels

[ $\mu \mathrm{g} / \mathrm{kg}$, microgram per kilogram]

\begin{tabular}{l|c}
\hline \multicolumn{1}{c|}{ Compound } & $\begin{array}{c}\text { Laboratory reporting } \\
\text { levels }(\boldsymbol{\mu g} \mathbf{g g})\end{array}$ \\
\hline Chlorpyrifos & 2.16 \\
Diazinon & 2.48 \\
Dimethoate & 1.93 \\
Disulfonton & 3.50 \\
Disulfonton sulfone & 2.26 \\
Ethion & 1.65 \\
Ethion monoxon & 1.61 \\
Ethoprop & 2.14 \\
O-ethyl-O-meth_ioate & 3.06 \\
Fenthion & 3.12 \\
Fonofos & 2.76 \\
Fonofos oxon & 1.99 \\
Malathion & 1.99 \\
Methidathion & 1.84 \\
Methyl parathion & 2.16 \\
Parathion & 1.90 \\
Phorate & 3.40 \\
Phorate oxon & 3.70 \\
Profenofos & 1.69 \\
Propetramphos & 2.40 \\
Sulfotepp & 2.24 \\
Sulprofos & 3.18 \\
Terbufos & 4.00 \\
Tribufos & 1.74 \\
Trithion & 1.73 \\
\hline
\end{tabular}

13.2 The Evergreen Lake sediment was dredged as part of routine dam maintenance, and sediment was collected from a mound that had been dredged several weeks prior to collection. The sediment sample was coarse with a substantial sand component.

13.3 The sediment sample collected from Clear Creek had been size-separated and consisted of particles less than $63 \mu \mathrm{m}$ in diameter. This sediment was light brown, and was received as a dry sample from the donor, unlike the Evergreen Lake sample, which was damp.

13.4 Eight samples of each sediment type were fortified with each compound at three different concentrations of 8,40 , and $80 \mu \mathrm{g} / \mathrm{kg}$. One sample for each sediment type was unfortified to determine any potential background contamination or interference for each matrix. 
13.5 All samples for a given matrix were extracted on the same day. Extracts were analyzed by GC/FPD, but different concentrations and matrices were analyzed at different times. Bias and variability data are listed in tables 7 through 15 (see following pages).

13.6 None of the method compounds were detected above the method detection limits in the unfortified reagent-sodium sulfate, the Evergreen Lake, or Clear Creek sediment samples.

13.7 Estimated MDLs were determined by fortifying eight reagent-sodium sulfate samples with the method compounds at $8 \mu \mathrm{g} / \mathrm{kg}$ and are reported in table 6 . the MDL was calculated by using the following equation:

$$
M D L=S \times t_{(n-1,1-\alpha=0.99)}
$$

where

$$
\begin{aligned}
& S=\text { standard deviation of the } \\
& n=\text { number of replicate analyses; }
\end{aligned}
$$

NOTE: More than one significant figure was included for the standard deviations used to calculate the MDL.

13.8 The estimated MDLs in table 6 reflect variation with eight separate reagent $O P$ spike sample preparations and GC/FPD calibrations. For most of the method compounds, these MDLs range from nearly half the initial laboratory reporting levels listed in table 5. The U.S. Environmental Protection Agency (1997) procedure for determining MDLs indicates that the samples should be spiked at a concentration nearly 2 to 5 times the expected MDL. The samples were spiked at $8 \mu \mathrm{g} / \mathrm{kg}$ for the MDL study for this method. The results for the MDL spiking experiments in this study resulted in MDLs that were about $1 / 8$ to $1 / 10$ of the spiking concentration. A spiking concentration of $4 \mu \mathrm{g} / \mathrm{kg}$ might result in slightly greater MDLs, because of slightly greater variations among spiked sample results.

13.9 Bias (percent mean recovery) and variability (percent relative standard deviation) are shown for all matrices in tables 7 through 15. Most compounds exhibit excellent performance with mean recoveries in excess of 60 percent and relative standard deviation (RSD) less than 15 percent in all three matrices.

13.10 Mean recoveries of method compounds spiked in Clear Creek samples ranged from 43 to 110 percent with average recoveries of 91 ( \pm 8 percent), 86 ( \pm 5 percent), and 74 ( \pm 7 percent) in samples spiked at concentrations of 8,40 , and $80 \mu \mathrm{g} / \mathrm{kg}$, respectively. Only ethion monoxon showed a low recovery of 43 percent in the Clear Creek matrix, although its recovery in other matrices was close to or greater than 60 percent.

13.11 Mean recoveries of method compounds spiked in Evergreen Lake sediment samples ranged from 62 to 123 percent with average recoveries of 86 ( \pm 7 percent), 88 ( \pm 6 percent), and 84 ( \pm 6 percent) in samples spiked at concentrations of 8,40 , and 80 $\mu \mathrm{g} / \mathrm{kg}$, respectively.

13.12 Mean recoveries of method compounds spiked in reagent sodium sulfate samples ranged from 57 to 101 percent with average recoveries of $75( \pm 5$ percent), 86 ( \pm 9 percent), and 78 ( \pm 7 percent) in samples spiked at concentrations of 8,40 , and 80 $\mu \mathrm{g} / \mathrm{kg}$, respectively.

13.13 The recoveries of ethoprop degradate (O-ethyl-O-meth_ioate) was excellent in the Evergreen Lake and Clear Creek sediment matrix (average 100 percent), but showed substantially low recovery ( 35 percent) in the sodium sulfate reagent matrix at $8 \mu \mathrm{g} / \mathrm{kg}$ concentration. It might be degrading in the spike mixture. Because of its low recovery in the sodium sulfate matrix, O-ethyl-O-meth_ioate will be routinely reported with an estimated " $E$ " concentration code in the field sample.

13.14 The compounds that were evaluated during early testing of the method and the reason they were not suitable for inclusion in this method are listed in table 16. All compounds listed in table 16 were deleted from the method because of very poor flame photometric detection response. 
Table 6. Bias and variability of method compounds spiked at 8 micrograms per kilogram in reagent sodium sulfate and estimated method detection limit

[conc., concentration; $\mu \mathrm{g} / \mathrm{kg}$, microgram per kilogram]

\begin{tabular}{|c|c|c|c|c|c|c|}
\hline Compound & $\begin{array}{l}\text { Number } \\
\text { of obser- } \\
\text { vations }\end{array}$ & $\begin{array}{c}\text { Mean } \\
\text { observed } \\
\text { conc. } \\
(\mu \mathrm{g} / \mathrm{kg})\end{array}$ & $\begin{array}{c}\text { Standard } \\
\text { deviation } \\
(\mu \mathrm{g} / \mathrm{kg})\end{array}$ & $\begin{array}{l}\text { Relative } \\
\text { standard } \\
\text { deviation } \\
\text { (percent) }\end{array}$ & $\begin{array}{c}\text { Bias } \\
\text { (percent } \\
\text { of true } \\
\text { conc.) }\end{array}$ & $\begin{array}{l}\text { Estimated } \\
\text { method } \\
\text { detection } \\
\text { limit }\end{array}$ \\
\hline Chlorpyrifos & 8 & 5.70 & 0.36 & 6.31 & 71.3 & 1.08 \\
\hline Diazinon & 8 & 5.70 & .41 & 7.27 & 71.2 & 1.24 \\
\hline Dimethoate & 8 & 6.38 & .32 & 5.06 & 79.7 & .996 \\
\hline Disulfoton & 8 & 3.27 & .58 & 17.85 & 40.9 & 1.75 \\
\hline Disulfoton sulfone & 8 & 7.34 & .38 & 5.13 & 91.7 & 1.13 \\
\hline Ethion & 8 & 6.25 & .28 & 4.40 & 78.1 & .824 \\
\hline Ethion monoxon & 8 & 6.24 & .27 & 4.32 & 78.0 & .807 \\
\hline Ethoprop & 8 & 5.31 & .36 & 6.72 & 66.3 & 1.07 \\
\hline O-Ethyl-O-meth_ioate* & 8 & 2.80 & .51 & 18.26 & 35.0 & 1.53 \\
\hline Fenthion & 8 & 6.60 & .52 & 7.86 & 82.5 & 1.56 \\
\hline Fonofos & 8 & 5.07 & .46 & 9.10 & 63.3 & 1.38 \\
\hline Fonofos oxon & 8 & 5.90 & .33 & 5.62 & 73.8 & .994 \\
\hline Malathion & 8 & 6.05 & .33 & 5.49 & 75.6 & .995 \\
\hline Methidathion & 8 & 6.14 & .31 & 5.00 & 76.8 & .921 \\
\hline Methyl parathion & 8 & 6.00 & .36 & 6.00 & 75.0 & 1.08 \\
\hline Parathion & 8 & 6.08 & .32 & 5.21 & 76.0 & .951 \\
\hline Phorate & 8 & 5.20 & .57 & 10.89 & 65.1 & 1.70 \\
\hline Phorate oxon & 8 & 6.63 & .62 & 9.28 & 82.9 & 1.85 \\
\hline Profenofos & 8 & 5.70 & .28 & 4.95 & 71.3 & .846 \\
\hline Propetamphos & 8 & 4.97 & .40 & 8.05 & 62.1 & 1.20 \\
\hline Sulfotepp & 8 & 4.89 & .37 & 7.64 & 61.2 & 1.12 \\
\hline Sulprofos & 8 & 6.85 & .53 & 7.74 & 85.6 & 1.59 \\
\hline Terbufos & 8 & 7.51 & .67 & 8.90 & 93.8 & 2.00 \\
\hline Tribufos & 8 & 6.21 & .29 & 4.66 & 77.7 & .868 \\
\hline Trithion & 8 & 6.18 & .29 & 4.66 & 77.3 & .863 \\
\hline
\end{tabular}

*Compound marked with an asterisk is permanently " $E$ " coded (estimated) in this method.

Not enough research was done on these compounds to clarify the exact reason for performance failure. Some analytes did not respond because of nondetectability by GC/FPD and low solubility in hexane, the solvent used to prepare the initial GC/FPD evaluation standard. In addition, photodecomposition or rapid degradation in sediment, volatility (excessive volatilization losses during sample preparation), and thermal liability of the compounds could be other reasons for unacceptable performance of these compounds.

\section{CONCLUSIONS}

This report presents a method for the routine analysis of 20 parent organophosphate pesticides and 5 pesticide degradates in sediment samples that include one compound (O-ethyl-O-methyl-S-propylphosphorothioate) to be reported permanently as estimated ("E"-coded) concentration. Recoveries of method compounds, except O-ethyl-O-methyl-Spropylphosphorothioate, in spiked reagent-sodium sulfate samples ranged from 41 to 101 percent. O-ethyl-O-methyl-S-propylphosphorothioate was the only compound that showed low recovery (35 percent). 
Single-operator method detection limits (determined in reagent-sodium sulfate matrix) ranged from 0.807 to $2.003 \mu \mathrm{g} / \mathrm{kg}$.

Previously, the National Water Quality Laboratory (NWQL) determined organophosphate pesticides recoverable in bottom sediment (method O-5104-83; NWQL laboratory schedule 1320 ) by using the U.S. Geological Survey methods described by Wershaw and others (1987). This original method included only six compounds (diazinon, ethion, malathion, methyl parathion, parathion and trithion). The present method will replace laboratory schedule 1320 . This new bottom-sediment method uses a gel-permeation chromatographic (GPC) procedure that improves organophosphate pesticide recoveries. This new method also expands the selected list of determined compounds from 6 to 25 . There are substantial advantages of this new method over the previously used method. The extensive preparation protocol provides cleaner extracts with increased signal-tonoise ratios and improved method detection limits. The GPC step removes or greatly reduces the inorganic sulfur in the extract.

Table 7. Bias and variability from eight determinations of the method compounds spiked at 8 micrograms per kilogram in reagent sodium sulfate

[conc., concentration]

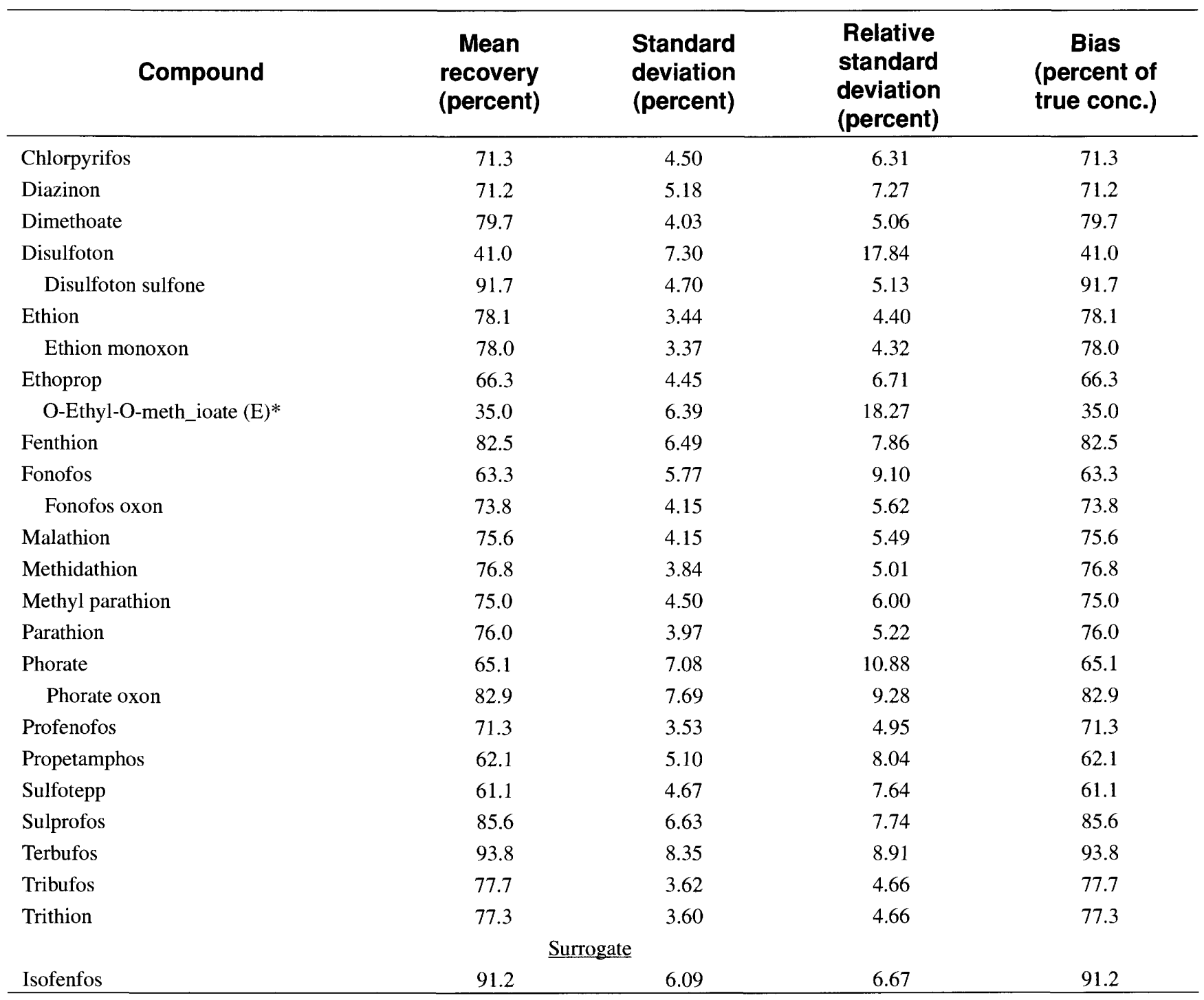

*Compound marked with an asterisk is permanently "E" coded (estimated) in this method. 
Table 8. Bias and variability from seven determinations of the method compounds spiked at 40 micrograms per kilogram in reagent sodium sulfate

[conc., concentration; ni, not in spike solution; na, not applicable]

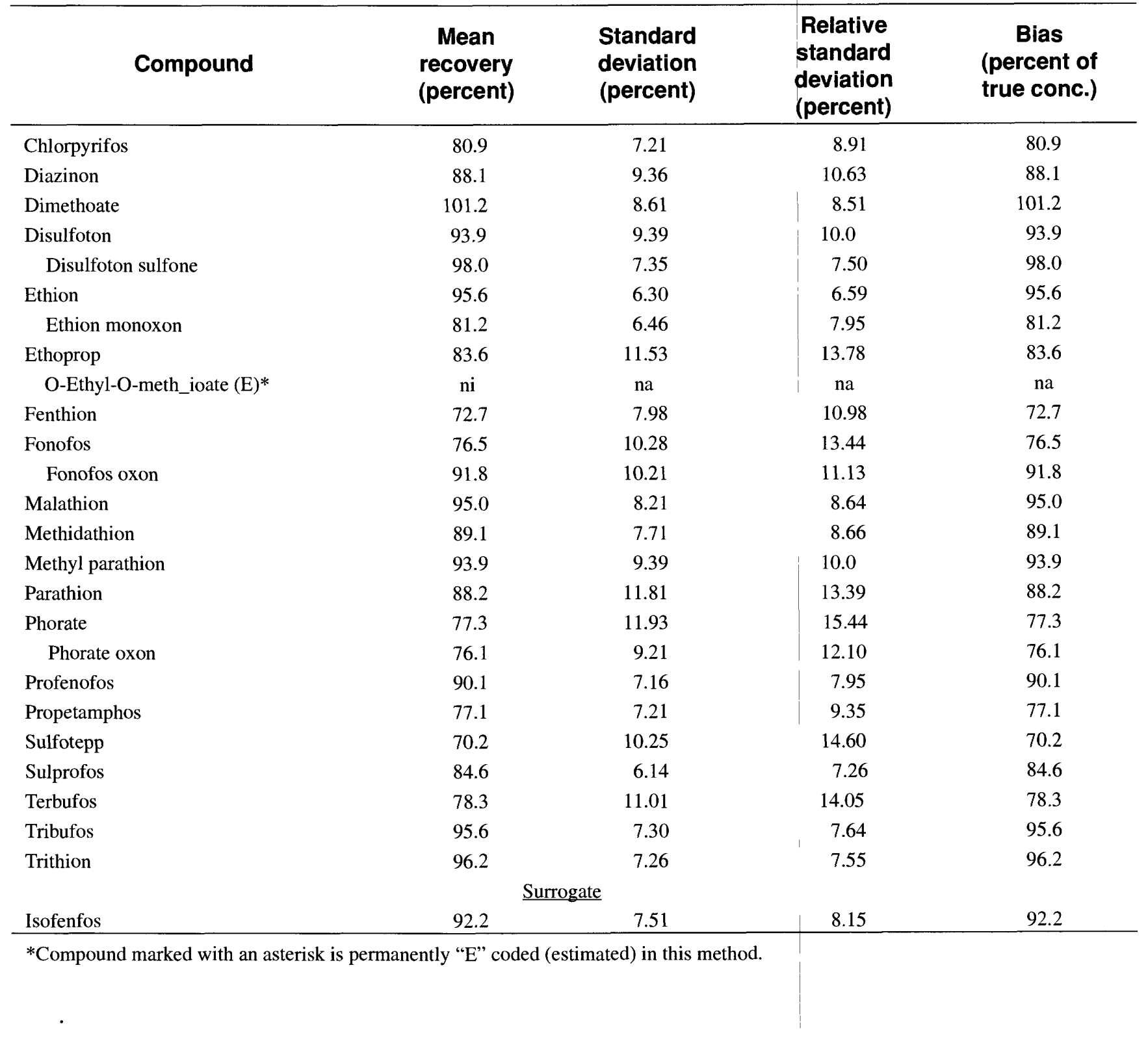


Table 9. Bias and variability from five determinations of the method compounds spiked at 80 micrograms per kilogram in reagent sodium sulfate

[conc., concentration; ni, not in spike solution; na, not applicable]

\begin{tabular}{|c|c|c|c|c|}
\hline Compound & $\begin{array}{c}\text { Mean } \\
\text { recovery } \\
\text { (percent) }\end{array}$ & $\begin{array}{l}\text { Standard } \\
\text { deviation } \\
\text { (percent) }\end{array}$ & $\begin{array}{l}\text { Relative } \\
\text { standard } \\
\text { deviation } \\
\text { (percent) }\end{array}$ & $\begin{array}{c}\text { Bias } \\
\text { (percent of } \\
\text { true conc.) }\end{array}$ \\
\hline Chlorpyrifos & 79.7 & 6.25 & 7.84 & 79.7 \\
\hline Diazinon & 84.8 & 6.14 & 7.24 & 84.8 \\
\hline Dimethoate & 99.8 & 5.36 & 5.37 & 99.8 \\
\hline Disulfoton & 78.0 & 6.91 & 8.86 & 78.0 \\
\hline Disulfoton sulfone & 94.5 & 4.61 & 4.88 & 94.5 \\
\hline Ethion & 69.4 & 12.36 & 17.81 & 69.4 \\
\hline Ethion monoxon & 56.5 & 10.09 & 17.84 & 56.5 \\
\hline Ethoprop & 70.9 & 11.65 & 16.44 & 70.9 \\
\hline O-Ethyl-O-meth_ioate (E)* & ni & na & na & na \\
\hline Fenthion & 67.4 & 5.29 & 7.86 & 67.4 \\
\hline Fonofos & 75.4 & 6.21 & 8.24 & 75.4 \\
\hline Fonofos oxon & 81.4 & 5.98 & 7.34 & 81.4 \\
\hline Malathion & 86.8 & 7.82 & 9.01 & 86.8 \\
\hline Methidathion & 90.3 & 4.01 & 4.44 & 90.3 \\
\hline Methyl parathion & 89.3 & 7.65 & 8.58 & 89.3 \\
\hline Parathion & 72.9 & 9.02 & 12.37 & 72.9 \\
\hline Phorate & 74.1 & 9.17 & 12.37 & 74.1 \\
\hline Phorate oxon & 74.8 & 6.55 & 8.76 & 74.8 \\
\hline Profenofos & 84.3 & 4.13 & 4.90 & 84.3 \\
\hline Propetamphos & 74.5 & 4.07 & 5.46 & 74.5 \\
\hline Sulfotepp & 55.1 & 11.00 & 19.98 & 55.1 \\
\hline Sulprofos & 82.2 & 5.01 & 6.08 & 82.2 \\
\hline Terbufos & 77.4 & 6.87 & 8.87 & 77.4 \\
\hline Tribufos & 74.2 & 11.82 & 15.93 & 74.2 \\
\hline Trithion & 81.1 & 10.51 & 12.96 & 81.1 \\
\hline \multicolumn{5}{|c|}{ Surrogate } \\
\hline Isofenfos & 93.3 & 4.52 & 4.84 & 93.3 \\
\hline
\end{tabular}

*Compound marked with an asterisk is permanently " $E$ " coded (estimated) in this method. 
Table 10. Bias and variability from seven determinations of the method compounds spiked at 8 micrograms per kilogram in Evergreen Lake sediment (Evergreen, Colo.)

[conc., concentration]

\begin{tabular}{|c|c|c|c|c|}
\hline Compound & $\begin{array}{l}\text { Mean } \\
\text { recovery } \\
\text { (percent) }\end{array}$ & $\begin{array}{l}\text { Standard } \\
\text { deviation } \\
\text { (percent) }\end{array}$ & $\begin{array}{l}\text { Relative } \\
\text { standard } \\
\text { deviation } \\
\text { (percent) }\end{array}$ & $\begin{array}{c}\text { Bias } \\
\text { (percent of } \\
\text { true conc.) }\end{array}$ \\
\hline Chlorpyrifos & 71.9 & 3.97 & 5.53 & 71.9 \\
\hline Diazinon & 76.0 & 3.97 & 5.22 & 76.0 \\
\hline Dimethoate & 90.9 & 6.01 & 6.71 & 90.9 \\
\hline Disulfoton & 101.7 & 23.11 & 22.72 & 101.7 \\
\hline Disulfoton sulfone & 82.6 & 6.90 & 8.35 & 82.6 \\
\hline Ethion & 74.8 & 3.91 & 5.23 & 74.8 \\
\hline Ethion monoxon & 74.7 & 5.07 & 6.79 & 74.7 \\
\hline Ethoprop & 81.0 & 4.79 & 5.92 & 81.0 \\
\hline O-Ethyl-O-meth_ioate $(\mathrm{E})^{*}$ & 102.1 & 13.84 & 13.56 & 102.1 \\
\hline Fenthion & 113.2 & 3.95 & 3.49 & 113.2 \\
\hline Fonofos & 77.4 & 4.20 & 5.43 & 77.4 \\
\hline Fonofos oxon & 66.6 & 4.83 & 7.25 & 66.6 \\
\hline Malathion & 77.7 & 4.94 & 6.37 & 77.7 \\
\hline Methidathion & 80.1 & 6.49 & 8.11 & 80.1 \\
\hline Methyl parathion & 90.6 & 6.56 & 7.24 & 90.6 \\
\hline Parathion & 88.3 & 3.41 & 3.87 & 88.3 \\
\hline Phorate & 102.3 & 11.19 & 10.94 & 102.3 \\
\hline Phorate oxon & 118.3 & 8.93 & 7.55 & 118.3 \\
\hline Profenofos & 69.9 & 5.39 & 7.71 & 69.9 \\
\hline Propetamphos & 74.8 & 3.88 & 5.19 & 74.8 \\
\hline Sulfotepp & 73.6 & 4.16 & 5.66 & 73.6 \\
\hline Sulprofos & 102.6 & 11.42 & 11.14 & 102.6 \\
\hline Terbufos & 104.0 & 11.68 & 11.24 & 104.0 \\
\hline Tribufos & 78.8 & 4.36 & 5.53 & 78.8 \\
\hline Trithion & 77.5 & 5.73 & 7.39 & 77.5 \\
\hline \multicolumn{5}{|c|}{ Surrogate } \\
\hline Isofenfos & 88.8 & 6.88 & 7.75 & 88.8 \\
\hline
\end{tabular}

*Compound marked with an asterisk is permanently " $E$ " coded (estimated) in this method. 
Table 11. Bias and variability from eight determinations of the method compounds spiked at 40 micrograms per kilogram in Evergreen Lake sediment (Evergreen, Colo.)

[conc., concentration; ni, not in spike solution; na, not applicable]

\begin{tabular}{|c|c|c|c|c|}
\hline Compound & $\begin{array}{c}\text { Mean } \\
\text { recovery } \\
\text { (percent) }\end{array}$ & $\begin{array}{l}\text { Standard } \\
\text { deviation } \\
\text { (percent) }\end{array}$ & $\begin{array}{l}\text { Relative } \\
\text { standard } \\
\text { deviation } \\
\text { (percent) }\end{array}$ & $\begin{array}{c}\text { Bias } \\
\text { (percent of } \\
\text { true conc.) }\end{array}$ \\
\hline Chlorpyrifos & 96.0 & 4.93 & 5.13 & 96.0 \\
\hline Diazinon & 97.5 & 4.30 & 4.41 & 97.5 \\
\hline Dimethoate & 99.1 & 4.47 & 4.51 & 99.1 \\
\hline Disulfoton & 77.9 & 4.23 & 5.43 & 77.9 \\
\hline Disulfoton sulfone & 116.8 & 9.35 & 8.01 & 116.8 \\
\hline Ethion & 84.2 & 11.99 & 14.24 & 84.2 \\
\hline Ethion monoxon & 81.6 & 5.32 & 6.52 & 81.6 \\
\hline Ethoprop & 93.4 & 4.13 & 4.42 & 93.4 \\
\hline O-Ethyl-O-meth_ioate (E)* & $\mathrm{ni}$ & na & na & na \\
\hline Fenthion & 69.2 & 8.46 & 12.23 & 69.2 \\
\hline Fonofos & 93.1 & 3.68 & 3.96 & 93.1 \\
\hline Fonofos oxon & 89.4 & 4.73 & 5.29 & 89.4 \\
\hline Malathion & 98.4 & 4.52 & 4.59 & 98.4 \\
\hline Methidathion & 82.2 & 6.24 & 7.59 & 82.2 \\
\hline Methyl parathion & 94.8 & 4.71 & 4.97 & 94.8 \\
\hline Parathion & 85.0 & 10.63 & 12.50 & 85.0 \\
\hline Phorate & 85.3 & 4.27 & 5.00 & 85.3 \\
\hline Phorate oxon & 78.8 & 4.16 & 5.28 & 78.8 \\
\hline Profenofos & 81.2 & 6.02 & 7.41 & 81.2 \\
\hline Propetamphos & 83.3 & 3.50 & 4.20 & 83.3 \\
\hline Sulfotepp & 80.6 & 2.86 & 3.55 & 80.6 \\
\hline Sulprofos & 78.5 & 9.72 & 12.38 & 78.5 \\
\hline Terbufos & 90.2 & 4.75 & 5.27 & 90.2 \\
\hline Tribufos & 93.9 & 7.20 & 7.67 & 93.9 \\
\hline Trithion & 82.8 & 11.35 & 13.71 & 82.8 \\
\hline \multicolumn{5}{|c|}{ Surrogate } \\
\hline Isofenfos & 98.7 & 5.86 & 5.94 & 98.7 \\
\hline
\end{tabular}

*Compound marked with an asterisk is permanently "E" coded (estimated) in this method. 
Table 12. Bias and variability from eight determinations of the method compounds spiked at 80 micrograms per kilogram in Evergreen Lake sediment (Evergreen, Colo.)

[conc., concentration; ni, not in spike solution; na, not applicable]

\begin{tabular}{|c|c|c|c|c|}
\hline Compound & $\begin{array}{c}\text { Mean } \\
\text { recovery } \\
\text { (percent) }\end{array}$ & $\begin{array}{l}\text { Standard } \\
\text { deviation } \\
\text { (percent) }\end{array}$ & $\begin{array}{l}\text { Relative } \\
\text { standard } \\
\text { deviation } \\
\text { (percent) }\end{array}$ & $\begin{array}{c}\text { Bias } \\
\text { (percent of } \\
\text { true conc.) }\end{array}$ \\
\hline Chlorpyrifos & 97.8 & 6.68 & 6.83 & 97.8 \\
\hline Diazinon & 99.5 & 6.75 & 6.78 & 99.5 \\
\hline Dimethoate & 95.5 & 6.28 & 6.58 & 95.5 \\
\hline Disulfoton & 80.7 & 5.92 & 7.34 & 80.7 \\
\hline Disulfoton sulfone & 122.7 & 9.65 & 8.56 & 122.7 \\
\hline Ethion & 70.2 & 5.60 & 7.99 & 70.2 \\
\hline Ethion monoxon & 64.0 & 6.12 & 9.56 & 64.0 \\
\hline Ethoprop & 80.2 & 6.20 & 7.74 & 80.2 \\
\hline O-Ethyl-O-meth_ioate $(\mathrm{E})^{*}$ & $\mathrm{ni}$ & na & na & na \\
\hline Fenthion & 70.2 & 6.22 & 8.87 & 70.2 \\
\hline Fonofos & 96.0 & 6.46 & 6.73 & 96.0 \\
\hline Fonofos oxon & 84.5 & 7.53 & 8.91 & 84.5 \\
\hline Malathion & 98.1 & 6.68 & 6.81 & 98.1 \\
\hline Methidathion & 78.7 & 6.57 & 8.34 & 78.7 \\
\hline Methyl parathion & 92.3 & 6.90 & 7.47 & 92.3 \\
\hline Parathion & 81.0 & 5.85 & 7.22 & 81.0 \\
\hline Phorate & 85.6 & 5.31 & 6.21 & 85.6 \\
\hline Phorate oxon & 79.3 & 5.24 & 6.61 & 79.3 \\
\hline Profenofos & 70.9 & 4.76 & 6.71 & 70.9 \\
\hline Propetamphos & 78.3 & 4.58 & 5.85 & 78.3 \\
\hline Sulfotepp & 62.3 & 6.26 & 10.04 & 62.3 \\
\hline Sulprofos & 76.7 & 6.66 & 8.68 & 76.7 \\
\hline Terbufos & 92.0 & 5.48 & 5.96 & 92.0 \\
\hline Tribufos & 82.8 & 5.84 & 7.06 & 82.8 \\
\hline Trithion & 78.4 & 7.20 & 9.17 & 78.4 \\
\hline \multicolumn{5}{|c|}{$\underline{\text { Surrogate }}$} \\
\hline Isofenfos & 101.1 & 6.35 & 6.28 & 101.1 \\
\hline
\end{tabular}

*Compound marked with an asterisk is permanently "E" coded (estimated) in this method. 
Table 13. Bias and variability from seven determinations of the method compounds spiked at 8 micrograms per kilogram in Clear Creek sediment (near Central City, Colo.)

[conc., concentration]

\begin{tabular}{|c|c|c|c|c|}
\hline Compound & $\begin{array}{c}\text { Mean } \\
\text { recovery } \\
\text { (percent) }\end{array}$ & $\begin{array}{l}\text { Standard } \\
\text { deviation } \\
\text { (percent) }\end{array}$ & $\begin{array}{l}\text { Relative } \\
\text { standard } \\
\text { deviation } \\
\text { (percent) }\end{array}$ & $\begin{array}{l}\text { Bias } \\
\text { (percent of } \\
\text { true conc.) }\end{array}$ \\
\hline Chlorpyrifos & 78.8 & 4.20 & 5.33 & 78.8 \\
\hline Diazinon & 79.5 & 5.14 & 6.46 & 79.5 \\
\hline Dimethoate & 102.8 & 6.34 & 6.17 & 102.8 \\
\hline Disulfoton & 87.2 & 29.85 & 34.22 & 87.2 \\
\hline Disulfoton sulfone & 93.0 & 4.67 & 5.02 & 93.0 \\
\hline Ethion & 82.4 & 3.47 & 4.22 & 82.4 \\
\hline Ethion monoxon & 86.8 & 5.05 & 5.82 & 86.8 \\
\hline Ethoprop & 83.2 & 3.92 & 4.71 & 83.2 \\
\hline O-Ethyl-O-meth_ioate $(\mathrm{E})^{*}$ & 99.4 & 10.95 & 11.01 & 99.4 \\
\hline Fenthion & 109.9 & 10.34 & 9.40 & 109.9 \\
\hline Fonofos & 80.5 & 4.62 & 5.75 & 80.5 \\
\hline Fonofos oxon & 81.1 & 7.25 & 8.95 & 81.1 \\
\hline Malathion & 86.0 & 5.24 & 6.09 & 86.0 \\
\hline Methidathion & 99.3 & 12.15 & 12.24 & 99.3 \\
\hline Methyl parathion & 101.6 & 6.23 & 6.13 & 101.6 \\
\hline Parathion & 95.8 & 4.90 & 5.11 & 95.8 \\
\hline Phorate & 103.4 & 12.97 & 12.54 & 103.4 \\
\hline Phorate oxon & 108.3 & 9.59 & 8.85 & 108.3 \\
\hline Profenofos & 86.4 & 6.05 & 7.00 & 86.4 \\
\hline Propetamphos & 79.2 & 3.79 & 4.78 & 79.2 \\
\hline Sulfotepp & 76.3 & 4.12 & 5.40 & 76.3 \\
\hline Sulprofos & 95.1 & 9.15 & 9.62 & 95.1 \\
\hline Terbufos & 103.0 & 8.77 & 8.52 & 103.0 \\
\hline Tribufos & 84.7 & 4.36 & 5.15 & 84.7 \\
\hline Trithion & 88.6 & 5.16 & 5.82 & 88.6 \\
\hline \multicolumn{5}{|c|}{ Surrogate } \\
\hline Isofenfos & 80.9 & 4.91 & 6.08 & 80.9 \\
\hline
\end{tabular}

*Compound marked with an asterisk is permanently " $E$ " coded (estimated) in this method. 
Table 14. Bias and variability from eight determinations of the method compounds spiked at 40 micrograms per kilogram in Clear Creek sediment (near Central City, Colo.)

[conc., concentration; ni, not in spike solution, na, not applicable]

\begin{tabular}{|c|c|c|c|c|}
\hline Compound & $\begin{array}{c}\text { Mean } \\
\text { recovery } \\
\text { (percent) }\end{array}$ & $\begin{array}{l}\text { Standard } \\
\text { deviation } \\
\text { (percent) }\end{array}$ & $\begin{array}{l}\text { Relative } \\
\text { standard } \\
\text { deviation } \\
\text { (percent) }\end{array}$ & $\begin{array}{c}\text { Bias } \\
\text { (percent of } \\
\text { true conc.) }\end{array}$ \\
\hline Chlorpyrifos & 86.7 & 13.63 & 15.72 & 86.7 \\
\hline Diazinon & 100.0 & 5.73 & 5.73 & 100.0 \\
\hline Dimethoate & 107.0 & 5.21 & 4.87 & 107.0 \\
\hline Disulfoton & 53.7 & 5.54 & 10.31 & 53.7 \\
\hline Disulfoton sulfone & 100.8 & 4.75 & 4.71 & 100.8 \\
\hline Ethion & 91.0 & 4.04 & 4.44 & 91.0 \\
\hline Ethion monoxon & 69.6 & 2.80 & 4.01 & 69.6 \\
\hline Ethoprop & 98.1 & 4.75 & 4.84 & 98.1 \\
\hline O-Ethyl-O-meth_ioate (E)* & $\mathrm{ni}$ & na & na & na \\
\hline Fenthion & 71.9 & 7.41 & 10.30 & 71.9 \\
\hline Fonofos & 92.7 & 5.13 & 5.53 & 92.7 \\
\hline Fonofos oxon & 83.4 & 4.16 & 4.99 & 83.4 \\
\hline Malathion & 98.0 & 5.07 & 5.17 & 98.0 \\
\hline Methidathion & 86.2 & 4.01 & 4.65 & 86.2 \\
\hline Methyl parathion & 98.9 & 4.13 & 4.18 & 98.9 \\
\hline Parathion & 89.5 & 13.90 & 15.52 & 89.5 \\
\hline Phorate & 72.7 & 4.68 & 6.44 & 72.7 \\
\hline Phorate oxon & 72.0 & 4.14 & 5.75 & 72.0 \\
\hline Profenofos & 82.1 & 3.44 & 4.19 & 82.1 \\
\hline Propetamphos & 84.9 & 4.65 & 5.48 & 84.9 \\
\hline Sulfotepp & 77.3 & 4.16 & 5.38 & 77.3 \\
\hline Sulprofos & 77.1 & 2.63 & 3.41 & 77.1 \\
\hline Terbufos & 83.7 & 4.04 & 4.82 & 83.7 \\
\hline Tribufos & 96.9 & 4.26 & 4.40 & 96.9 \\
\hline Trithion & 91.5 & 3.80 & 4.15 & 91.5 \\
\hline \multicolumn{5}{|c|}{ Surrogate } \\
\hline Isofenfos & 92.9 & 7.71 & 8.30 & 92.9 \\
\hline
\end{tabular}

*Compound marked with an asterisk is permanently " $E$ " coded (estimated) in this method. 
Table 15. Bias and variability from eight determinations of the method compounds spiked at 80 micrograms per kilogram in Clear Creek sediment (near Central City, Colo.)

[conc., concentration; ni, not in spike solution, na, not applicable]

\begin{tabular}{|c|c|c|c|c|}
\hline Compound & $\begin{array}{c}\text { Mean } \\
\text { recovery } \\
\text { (percent) }\end{array}$ & $\begin{array}{l}\text { Standard } \\
\text { deviation } \\
\text { (percent) }\end{array}$ & $\begin{array}{l}\text { Relative } \\
\text { standard } \\
\text { deviation } \\
\text { (percent) }\end{array}$ & $\begin{array}{c}\text { Bias } \\
\text { (percent of } \\
\text { true conc.) }\end{array}$ \\
\hline Chlorpyrifos & 88.8 & 6.09 & 6.86 & 88.8 \\
\hline Diazinon & 91.4 & 7.22 & 7.90 & 91.4 \\
\hline Dimethoate & 88.8 & 6.53 & 7.36 & 88.8 \\
\hline Disulfoton & 57.7 & 9.05 & 15.69 & 57.7 \\
\hline Disulfoton sulfone & 93.3 & 9.92 & 10.64 & 93.3 \\
\hline Ethion & 59.4 & 4.48 & 7.55 & 59.4 \\
\hline Ethion monoxon & 43.2 & 3.23 & 7.47 & 43.2 \\
\hline Ethoprop & 69.3 & 5.53 & 7.97 & 69.3 \\
\hline O-Ethyl-O-meth_ioate $(\mathrm{E})^{*}$ & $\mathrm{ni}$ & na & na & na \\
\hline Fenthion & 67.4 & 5.01 & 7.44 & 67.4 \\
\hline Fonofos & 89.2 & 7.91 & 8.87 & 89.2 \\
\hline Fonofos oxon & 77.9 & 7.61 & 9.77 & 77.9 \\
\hline Malathion & 83.3 & 5.88 & 7.06 & 83.3 \\
\hline Methidathion & 78.2 & 8.41 & 10.78 & 78.2 \\
\hline Methyl parathion & 85.2 & 6.03 & 7.08 & 85.2 \\
\hline Parathion & 70.9 & 5.35 & 7.55 & 70.9 \\
\hline Phorate & 68.5 & 6.76 & 9.87 & 68.5 \\
\hline Phorate oxon & 70.6 & 7.01 & 9.94 & 70.6 \\
\hline Profenofos & 75.6 & 7.99 & 10.57 & 75.6 \\
\hline Propetamphos & 77.8 & 6.34 & 8.15 & 77.8 \\
\hline Sulfotepp & 50.3 & 4.26 & 8.48 & 50.3 \\
\hline Sulprofos & 66.3 & 9.74 & 14.70 & 66.3 \\
\hline Terbufos & 83.2 & 8.59 & 10.33 & 83.2 \\
\hline Tribufos & 66.3 & 4.68 & 7.05 & 66.3 \\
\hline Trithion & 67.9 & 4.54 & 6.69 & 67.9 \\
\hline \multicolumn{5}{|c|}{$\underline{\text { Surrogate }}$} \\
\hline Isofenfos & 103.7 & 9.80 & 9.45 & 103.7 \\
\hline
\end{tabular}

*Compound marked with an asterisk is permanently " $\mathrm{E}$ " coded (estimated) in this method. 
Table 16. Compounds tested and deleted from this method because of very poor flame photometric detection response

\begin{tabular}{|c|c|}
\hline \multicolumn{2}{|c|}{ Compounds tested } \\
\hline $\begin{array}{c}\text { Parent } \\
\text { compounds }\end{array}$ & Degradates \\
\hline Acephate & Azinphos methyl oxon \\
\hline Cadusaphos & Chlorpyrifos oxon \\
\hline Dichlorovos & Diazinon oxon \\
\hline Dicrotophos & Dimethoate oxon \\
\hline Fenamiphos & Fenamiphos sulfone \\
\hline Guthion & Fenamiphos sulfoxide \\
\hline Metamidophos & Fenthionsulfone \\
\hline Naled & Malaoxon \\
\hline Phosmet & Paraoxon methyl \\
\hline \multirow[t]{4}{*}{ Temephos } & Paraoxon ethyl \\
\hline & Phosmet oxon \\
\hline & Temephos sulfoxide \\
\hline & Terbufos oxygen analog sulfone \\
\hline
\end{tabular}

\section{REFERENCES CITED}

Childress, C.J., Foreman, W.T., Connor, B.F., and Maloney, T.J., 1999, New reporting procedures based on longterm method detection levels and some considerations for interpretations of water-quality data provided by the U.S. Geological Survey National Water Quality Laboratory: U.S. Geological Survey Open-File Report 99-193, $19 \mathrm{p}$.

Fishman, M.J., 1993, ed., Methods of analysis by the U.S. Geological Survey National Water Quality Laboratory-Determination of inorganic and organic constituents in water and fluvial sediments: U.S. Geological Survey Open-File Report 93-125, 217 p.

Foreman, W.T., Connor, B.F., Furlong, E.T., Vaught, D.G., and Merten, L.M., 1995, Methods of analysis by the U.S. Geological Survey National Water Quality Laboratory-Determination of organochlorine pesticides and polychlorinated biphenyls in bottom sediment by dual capillary-column gas chromatography with electron-capture detection: U.S. Geological Survey Open-File Report 95-140, 78 p.

Furlong, E.T., Vaught, D.G., Merten, L.M., Foreman, W.T., and Gates, P.M., 1995, Methods of analysis by the U.S. Geological Survey National Water Quality Laboratory-Determination of semivolatile organic compounds in bottom sediment by solvent extraction, gel permeation chromatographic fractionation, and capillary-column gas chromatography/mass spectometry: U.S. Geological Survey Open-File Report 95-719, $67 \mathrm{p}$.
Jha, V.K., and Wydoski, D.S., 2002, Methods of analysis by the U.S. Geological Survey National Water Quality Laboratory-Determination of organophosphate pesticides in filtered water by gas chromatography with flame photometric detection: U.S. Geological Survey Water-Resources Investigations Report 02-4071, 40 p.

Pirkey, K.D., and Glodt, S.R., 1998, Quality control at the U.S. Geological Survey National Water Quality Laboratory: U.S. Geological Survey Fact Sheet FS026-98, 4 p.

Sandstrom, M.W., Stroppel, M.E., Foreman, W.T., and Schroeder, M.P., 2001, Methods of analysis by the U.S. Geological Survey National Water Quality Laboratory-Determination of moderate-use pesticides and selected degradates in water by $\mathrm{C}-18$ solid-phase extraction and capillary-column gas chromatography/ mass spectrometry with selected-ion monitoring (methods 2002/2011): U.S. Geological Survey WaterResources Investigations Report 01-4098, $70 \mathrm{p}$.

Smith, J.A., Witkowski, P.J., and Fusillo, T.V., 1988,

Manmade organic compounds in the surface waters of the United States-A review of current understanding: U.S. Geological Survey Circular 1007.

U.S. Environmental Protection Agency, 1997, Guidelines establishing test procedures for the analysis of pollutants (App. B, Part 136, Definition and procedures for the determination of the method detection limit): U.S. Code of Federal Regulations, Title 40, p. 265-267.

U.S. Geological Survey, 1997 to present, National field manual for the collection of water-quality data: U.S. Geological Survey Techniques of Water-Resources Investigations Report, book 9, chaps. A1-A9, variously paged. Also available on the World Wide Web; accessed May 2, 2002, at URL http://water.usgs.gov/ owq/Field Manual. Updates and revisions are ongoing and may be accessed at URL http://water.usgs.gov/ owq/FieldManual/mastererrata.html

Wershaw, R.L., Fishman, M.J., Grabbe, R.R., and Lowe, L.E., eds., 1987, Methods for the determination of organic substances in water and fluvial sediments: U.S. Geological Survey Techniques of Water-Resources Investigations Report, book 5, chap. A3, p. 27-31.

Winslow, S.D., Prakash, B., Domono, M.M., Pepich, B.V., and Munch, D.J., 2001, Considerations necessary in gathering occurrence data for selected unstable compounds in the USEPA unregulated contaminant candidate list in USEPA method 526: Environmental Science and Technology, v. 35, p. 1851-1858. 

9 Printed on recycled paper 